Universidade de São Paulo

Faculdade de Economia, Administração e Contabilidade de Ribeirão Preto

Departamento de Economia

Programa de Pós-graduação em Economia - Área: Economia Aplicada

\title{
Investimento do governo no mercado de ações como compensação do financiamento de campanhas eleitorais.
}

Prof. Dr. Sergio Naruhiko Sakurai

Ribeirão Preto - Brasil

2016 
Prof. Dr. Marco Antonio Zago

Reitor da Universidade de São Paulo

Prof. Dr. Dante Pinheiro Martinelli

Diretor da Faculdade de Economia, Administração e Contabilidade de Ribeirão Preto

Prof. Dr. Renato Leite Marcondes

Chefe do Departamento de Economia

Prof. Dr. Cláudio Ribeiro de Lucinda

Coordenador do Programa de Pós-Graduação em Economia - Área:

Economia Aplicada 


$$
\text { Universidade de São Paulo }
$$

Faculdade de Economia, Administração e Contabilidade de Ribeirão Preto Departamento de Economia

Programa de Pós-graduação em Economia - Área: Economia Aplicada

\title{
Investimento do governo no mercado de ações como compensação do financiamento de campanhas eleitorais.
}

\begin{abstract}
Dissertação de Mestrado submetida ao Programa de Pós-Graduação em Economia da Faculdade de Economia, Administração e Contabilidade de Ribeirão Preto da Universidade de São Paulo, para a obtenção do título de Mestre em Ciências.Versão Corrigida. A original encontra-se disponível na FEA-RP/USP.
\end{abstract}

IGOR SILVA BUENO

Orientador: Prof. Dr. Sergio Naruhiko Sakurai

Ribeirão Preto - Brasil

2016 
Autorizo a reprodução e divulgação total ou parcial deste trabalho, por qualquer meio convencional ou eletrônico, para fins de estudo e pesquisa, desde que citada a fonte.

Bueno, Igor Silva

Investimento do governo no mercado de ações como compensação do financiamento de campanhas eleitorais./ IGOR SILVA BUENO; Orientador: Prof. Dr. Sergio Naruhiko Sakurai

Ribeirão Preto - Brasil, 2016- 70 p. : il.

Dissertação (Mestrado) - Universidade de São Paulo, 2016.

1. Eleições. Financiamento Eleitoral. Doações Eleitorais. Diferenças em Diferenças. 2. Financiamento Eleitoral. 3. Doações Eleitorais. 4. Diferenças em Diferenças. I. Orientador: Sergio Naruhiko Sakurai. II. Universidade De São Paulo - Campus Ribeirão Preto. III. Faculdade de Economia, Administração e Contabilidade. IV. Investimento do governo no mercado de ações como compensação do financiamento de campanhas eleitorais. 
Este trabalho é dedicado à minha família, núcleo de todas as minhas forças e virtudes. 


\section{Agradecimentos}

Agradeço meu orientador Sergio Naruhiko Sakurai pelo convite e oportunidade de estudar na Faculdade de Economia, Administração e Contabilidade de Ribeirão Preto. Você estava certo, realmente me surpreendi com o que encontrei. Também agradeço seu apoio e orientação no desenvolvimento deste trabalho.

Agradeço os professores que se empenharam em contribuir para minha formação, mesmo quando eu mesmo teimei em fazê-lo. Agradeço aos colegas de curso, que proporcionaram momentos de muita alegria e crescimento. Fernanda, Daniel, Ricardo, Marcos, Gabriel, Juliana, Pedro, Marcelo, Victória, Rodrigo, Caio e Karen, lembrarei de todos com muito carinho. Em especial agradeço Fernanda Mundim, Daniel Prado, Rodrigo Borges e Victória Martinez pelo apoio nos momentos de maior dificuldade.

Por fim, agradeço à cidade de Ribeirão Preto por ter proporcionado uma estada tão agradável durante o período de mestrado. Nunca me esquecerei dessa cidade. Sentirei saudades. 
"Não há doações legais no Brasil, mas sim empréstimos a serem cobrados posteriormente a juros altos dos beneficiários das contribuições quando no exercício dos cargos"

- Paulo Roberto Costa, ex-diretor da Petrobras e delator da Operação Lava Jato 


\section{Resumo}

BUENO, I. S. Investimento do governo no mercado de ações como compensação do financiamento de campanhas eleitorais. 2016. Dissertação (Mestrado) - Faculdade de Economia, Administração e Contabilidade de Ribeirão Preto, Universidade de São Paulo, Ribeirão Preto, 2016.

Este trabalho visa contribuir para a compreensão dos incentivos que permeiam os agentes envolvidos no financiamento de campanhas eleitorais. Por meio de evidências empíricas reunidas a partir do contexto do financiamento de campanhas brasileiras, a compra de ações de empresas de capital aberto por parte do governo é analisada como possível mecanismo de compensação do financiamento de campanhas eleitorais. A análise é feita comparando a participação do governo no capital de sociedades anônimas doadoras e não doadoras de recursos para financiamento de campanhas usando o método de Diferenças em Diferenças. Por meio dessa metodologia, identificou-se, particularmente na eleição de 2010, um efeito positivo do financiamento eleitoral sobre o investimento do governo em ações de empresas financiadoras.

Palavras-chaves: Eleições. Financiamento Eleitoral. Doações Eleitorais. Diferenças em Diferenças.

Código JEL: D72 


\section{Abstract}

BUENO, I. S. Government investment in the stock market as compensation for campaign financing. 2016. Dissertação (Mestrado) - Faculdade de Economia, Administração e Contabilidade de Ribeirão Preto, Universidade de São Paulo, Ribeirão Preto, 2016.

This study aims to contribute to the literature by investigating the incentives that pervade agents involved in electoral campaign funding. By means of empirical evidence gathered from the Brazilian electoral financing context, government investment in stocks is analyzed as a possible compensation mechanism for electoral campaign financing. The study investigates government investments in stocks comparing corporations that have supported electoral campaigns and those that have not, by applying the Differences-inDifferences method. By this method, a positive effect of electoral financing on government investment in companies stocks was identified in the 2010 electoral cycle. However, the empirical tests suggest no effect in 2002 and 2006 elections.

Key-words: Elections. Election Finance. Electoral Donations. Differences in Differences.

JEL Cod: D72 


\section{Lista de ilustrações}

Figura 1 - Diagramas de Doação . . . . . . . . . . . . . . . 22

Figura 2 - Estrutura do Repositório de Dados Eleitorais . . . . . . . . . . . . 22

Figura 3 - Distribuição do Valor das Doações 2002 . . . . . . . . . . . . . . . . 27

Figura 4 - Distribuição do Valor das Doações 2006 . . . . . . . . . . . . . . 27

Figura 5 - Distribuição do Valor das Doações 2010 . . . . . . . . . . . . . . . . 28

Figura 6 - Trajetórias de ShareGov por Eleição - Exercício Global 2002 . . . . . . 35

Figura 7 - Trajetórias de ShareGov por Eleição - Exercício Global 2006 . . . . . . 36

Figura 8 - Trajetórias de ShareGov por Eleição - Exercício Global 2010 . . . . . . 36

Figura 9 - Trajetórias de ShareGov por Eleição - Exercício Governado 2002 . . . 37

Figura 10 - Trajetórias de ShareGov por Eleição - Exercício Governador 2006 . . 37

Figura 11 - Trajetórias de ShareGov por Eleição - Exercício Governador 2010 . . 38 


\section{Lista de tabelas}

Tabela 1 - Valor de Contribuições Eleitorais por Cargo . . . . . . . . . . . . . . . 24

Tabela 2 - Valor de Contribuições Eleitorais por Candidato . . . . . . . . . . . . 24

Tabela 3 - Valor de Contribuições por Fonte de Recurso . . . . . . . . . . . . . . 25

Tabela 4 - Porcentagem do Financiamento Eleitoral de Empresas . . . . . . . . . 26

Tabela 5 - Empresas de Capital Aberto no Financiamento Eleitoral . . . . . . . . 26

Tabela 6 - Variáveis Financeiras de Controle . . . . . . . . . . . . . . . 28

Tabela 7 - Participação do Governo na Composição Acionária das Empresas Bovespa 31

Tabela 8 - Diferenças em Diferenças . . . . . . . . . . . . . 31

Tabela 9 - Composição Setorial das Empresas Estudadas - Exercício Global . . . . 39

Tabela 10 - Composição Setorial das Empresas Estudadas - Exercício Governador . 39

Tabela 11 - Resultados Exercício Global . . . . . . . . . . . . . . . . . 43

Tabela 12 - Resultados Exercício Governador . . . . . . . . . . . . . . . . 44

Tabela 13 - Lista de Acionistas Classificados como Agentes do Governo . . . . . . . 52

Tabela 14 - Lista de Empresas Exercício Global 2002 . . . . . . . . . . . . . . 55

Tabela 15 - Lista de Empresas Exercício Global 2006 . . . . . . . . . . . . . 57

Tabela 16 - Lista de Empresas Exercício Global 2010 . . . . . . . . . . . . . . . 59

Tabela 17 - Lista de Empresas Exercício Governador 2002 . . . . . . . . . . . . . 62

Tabela 18 - Lista de Empresas Exercício Governador 2006 . . . . . . . . . . . . . . 65

Tabela 19 - Lista de Empresas Exercício Governador 2010 . . . . . . . . . . . . 67 


\section{Sumário}

INTRODUÇÃo $\ldots \ldots \ldots \ldots \ldots \ldots \ldots \ldots$

2 FINANCIAMENTO ELEITORAL NO BRASIL E NO MUNDO . . . 14

LITERATURA $\ldots \ldots \ldots \ldots \ldots \ldots \ldots \ldots$

4

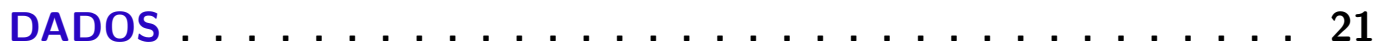

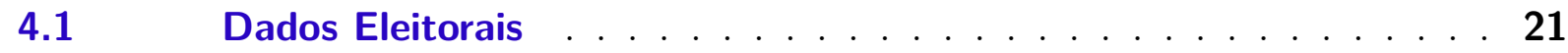

4.2 Dados Financeiros . . . . . . . . . . . . . . . 27

$4.3 \quad$ Variável Dependente . . . . . . . . . . . . . . . . . . . . 29

$4.4 \quad$ Amostragem . . . . . . . . . . . . . . . . . . 31

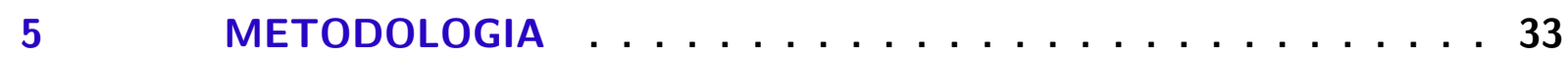

$5.1 \quad$ Estratégia Empírica $\ldots \ldots \ldots \ldots \ldots$

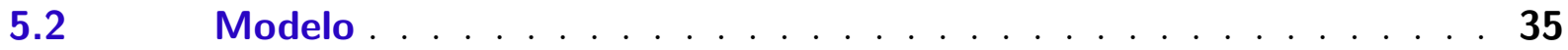

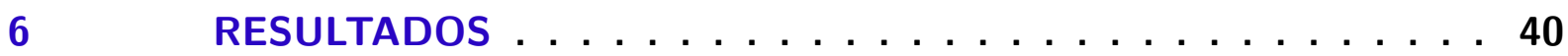

$6.1 \quad$ Exercício Global . . . . . . . . . . . . . . . . . . . . . 40

6.2 Exercício Governador . . . . . . . . . . . . . . . . . . 41

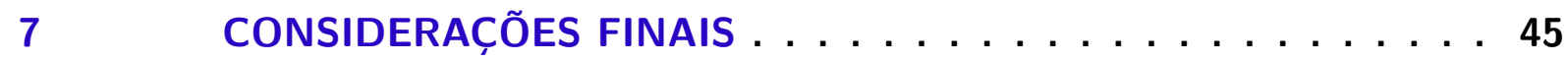

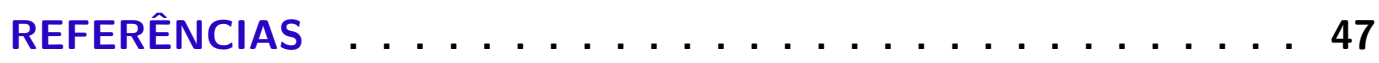

$\begin{array}{ll}\text { APÊNDICES } & 49\end{array}$

APÊNDICE A - PROTOCOLO DE CONSTRUÇÃO DO PAINEL PARA GOVERNADORES . . . . . . . . 50

APÊNDICE B - LISTA DE ACIONISTAS CLASSIFICADOS COMO AGENTES DO GOVERNO . . . . . . . . 52

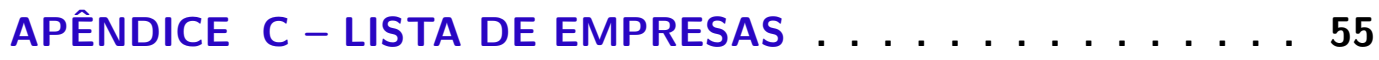




\section{Introdução}

Eleições são o ponto central do processo democrático. É por meio delas que a sociedade escolhe seus representantes políticos que, para se elegerem, tentam angariar votos do eleitorado apresentando suas propostas de governo. Para que essas propostas cheguem ao conhecimento dos eleitores, os candidatos usam campanhas eleitorais. Essa dinâmica evidencia a importância das campanhas na democracia. Campanhas são uma ferramenta de propaganda e autopromoção de candidatos a cargos políticos, que desempenham papel fundamental na determinação dos resultados eleitorais.

Em função desse papel, grandes volumes de recursos são aplicados todos os anos e de forma crescente - em campanhas eleitorais pelo mundo. As campanhas brasileiras de 2010, por exemplo, mobilizaram mais de 4,2 bilhões de reais segundo dados do Tribunal Superior Eleitoral (TSE). Na Europa Ocidental, analistas estimam que as campanhas ucranianas de 2012 somam gastos entre 850 milhões e 2.5 bilhões de dólares. ${ }^{1}$ Nesse mesmo ano, somente as campanhas para a presidência dos Estados Unidos movimentaram mais de 2,6 bilhões de dólares segundo dados da organização não governamental americana Center for Responsive Politics.

Os altos valores envolvidos no financiamento eleitoral incitam questões sobre o tema: Qual a origem desses recursos? Quem são os agentes financiadores de campanhas eleitorais? Por que existem pessoas e organizações dispostas a financiar campanhas eleitorais? Parte do objetivo da agenda de pesquisa em Economia Eleitoral - na área de Financiamento Eleitoral - consiste em esclarecer essas indagações. Este trabalho visa contribuir com a literatura ao prover novos resultados que ajudam a esclarecer essas dúvidas dentro do contexto de financiamento eleitoral brasileiro.

A compreensão do financiamento eleitoral começa com a identificação dos principais agentes econômicos envolvidos. Os modelos relacionados ${ }^{2}$ investigam, em sua maioria, a interação entre dois agentes centrais: candidatos a cargos políticos e agentes financiadores. A interação entre esses agentes consiste em um jogo no qual os financiadores doam para campanhas eleitorais em troca de benefícios que candidatos eleitos podem oferecer usando sua influência política de seu cargo.

O valor das doações para campanhas é um elemento essencial nesse contexto. O mesmo vale para a definição dos benefícios que candidatos eleitos podem proporcionar. Examinando empresas no papel de agentes financiadores, a literatura cita a promoção de contratos junto ao governo, a isenção de impostos e a promoção de crédito, entre outros,

1 Ballington, Austin e Tjernstrom (2014), página 188

2 Que serão apresentados na revisão de literatura desta dissertação 
como potenciais benefícios.

Este trabalho analisa a compra de ações por parte do governo como forma de compensação do financiamento eleitoral. Pretende-se aqui investigar se empresas que financiam campanhas eleitorais recebem posteriormente maior investimento do governo em suas ações devido à influência política de candidatos financiados.

As empresas estudadas consistem no conjunto das sociedades anônimas listadas na Bolsa de Valores de São Paulo. Dentro do quadro de composição acionária dessas empresas, os acionistas são classificados como privados ou governamentais. A regra de classificação fundamenta-se na legislação orçamentária do Brasil. A participação do governo nos quadros acionários equivale à soma da participação dos acionistas classificados como governo.

A análise consiste na comparação da participação acionária do governo em dois grupos: empresas doadoras e não doadoras de campanha, antes e depois das eleições. Esse processo é aplicado nas eleições de 2002, 2006, 2010 em dois exercícios distintos: um considerando doações para todos os cargos, que será chamado Exercício Global, e outro isolando doações às eleições para Governador Estadual, denominado Exercício Governador.

Os dados eleitorais usados nesta análise foram obtidos junto ao TSE. A escolha dos anos analisados é resultado exclusivo da disponibilidade de dados. Os dados financeiros foram obtidos junto à Economática e a opção pela análise de empresas de capital aberto é igualmente fruto da disponibilidade de informações. A extensão do exercício a duas esferas eleitorais - global e estadual - visa conferir maior grau de confiabilidade aos mecanismos de influência política assumidos.

A comparação é feita pelo método Diferenças em Diferenças, em que o tratamento consiste na contribuição para campanhas eleitorais e o controle na ausência de contribuição. A intervenção temporal consiste no ano em que a eleição é realizada. Assume-se que a influência política que causa variação na participação acionária governamental se manifesta nos quatro anos de governo posteriores à eleição estudada.

Os resultados dos testes empíricos aplicados às eleições de 2010 sugerem aumento do investimento do governo em ações de empresas que doaram recursos para campanhas eleitorais em comparação às empresas que não doaram. Entretanto, o conjunto de resultados dos anos analisados sugere que não há evidência suficiente para assumir que a compra de ações por parte do governo seja efetivamente um mecanismo pelo qual se desenvolve a barganha entre candidatos eleitorais e agente financiadores.

O restante do trabalho está divido da seguinte maneira: a segunda seção consiste num panorama do financiamento eleitoral no Brasil e no mundo. A terceira seção revisa a literatura relacionada ao financiamento eleitoral. A quarta seção, apresenta os dados. A quinta seção, apresenta a metodologia usada. A sexta seção, apresenta os resultados. A sétima e última seção destina-se às considerações finais. 


\section{Financiamento Eleitoral no Brasil e no Mundo}

Na atualidade, uma parcela significativa dos países do mundo adota a democracia como forma de governo. Segundo o relatório Democracy Index ${ }^{3}$ da Economist Intelligence Unit, vinculada à revista The Economist, aproximadamente $47 \%$ dos países reconhecidos pela ONU organizam seus governos com base no regime democrático.

O princípio fundamental deste sistema reside na ideia de que o povo é o detentor do poder, e que qualquer cidadão está apto a exercê-lo por meio de cargos eletivos do poder público. Assegurar o funcionamento desse princípio é o objetivo precípuo das eleições democráticas. Nelas, os governantes são escolhidos pela sociedade em função de suas propostas de governo e não por fatores como hereditariedade ou força militar.

$\mathrm{Na}$ democracia, partidos políticos e candidatos competem por votos a fim de se eleger. Para conquistar esses votos, a principal ferramenta usada pelos candidatos é a campanha eleitoral. Segundo Gomes (2012) campanha eleitoral consiste:" [...] no complexo de atos e procedimentos técnicos empregados por candidato com vistas a obter o voto dos eleitores e lograr êxito na disputa de cargo público-eletivo". Pierre (2008) define campanha eleitoral como: " a propaganda política dos candidatos a cargos executivos ou legislativos, em época de eleição". ${ }^{4}$

As campanhas eleitorais exercem grande influência sobre o resultado das eleições. Segundo Morton e Cameron (1992) as despesas em campanhas aumentam decisivamente a probabilidade de eleição de um candidato. Assim sendo, o volume de recursos nelas aplicado é uma variável crítica para obter-se êxito em um pleito eleitoral. Em função disso, candidatos têm interesse em maximizar esse volume.

As despesas de campanha aumentam conforme o número de eleitores e a abrangência política do cargo em disputa. Sem a possibilidade de financiamento, candidatar-se a um cargo político-eletivo restringe-se a indivíduos com alto poder financeiro. Nesse sentido, o financiamento eleitoral desempenha funções benéficas para o sistema democrático na medida em que permite que mais cidadãos tenham acesso a candidaturas, proporcionandolhes a oportunidade de serem conhecidos pela sociedade, explicando seus objetivos e propostas de governo.

Apesar de sua importância no processo eleitoral, o financiamento de campanhas se torna um problema quando a influência das doações prevalece sobre ideais democráticos.

3 Unit (2015)

4 Ambos os autores estão presentes na bibliografia recomendada pelo Tribunal Superior Eleitoral no relatório Eleitoral (2012) 
Isso ocorre, por exemplo, quando governantes se preocupam em representar interesses de grupos financiadores em detrimento dos interesses da sociedade. O desenvolvimento desse cenário cria um sistema propício ao abuso de grandes corporações interessadas na influência política dos governantes.

Nesse contexto, o financiamento eleitoral aproxima-se de um investimento, em que contribuições são feitas exclusivamente visando benefícios provenientes da influência política de cargos públicos. Esses benefícios incluem promoção de contratos de prestação de serviço e vendas junto ao governo, isenção de impostos, promoção de crédito junto à agências de fomento do governo, resolução de problemas com agências reguladoras, dentre outros.

A barganha que ocorre entre financiadores e candidatos gera várias adversidades para a sociedade. Ballington, Austin e Tjernstrom (2014) citam escândalos fiscais, má gestão de recursos públicos, financiamento eleitoral por atividades ilícitas e processos relacionados à corrupção como desdobramentos associados ao financiamento eleitoral desprovido de regulação.

Além disso, o financiamento desproporcional entre candidatos desequilibra as chances de vitória nas eleições em favor daqueles com mais recursos, enfraquecendo a equidade na competição eleitoral. O ápice desse processo ocorre quando as preferências e interesses da sociedade são marginalizados em função da influência financeira e as eleições se resumem a uma competição por recursos.

Visando combater esses problemas, instituições internacionais envolvidas na pesquisa e avaliação de regimes democráticos, como o International Institute for Democracy and Electoral Assistence, apontam a regulação do financiamento eleitoral como uma medida decisiva. Segundo a Global Commission on Elections, Democracy and Security, a necessidade de regulamentar o financiamento eleitoral é o maior desafio para a manutenção da integridade das eleições em todo o mundo.

Esses núcleos consideram o aumento da transparência no financiamento eleitoral como um fator determinante no combate a processos de corrupção e na manutenção da credibilidade dos regimes democráticos no mundo. Alinhados a esse raciocínio, governos implementam regulações que objetivam limitar o papel dos recursos financeiros nas eleições e mitigar a dinâmica de compensação entre financiadores e candidatos.

As formas de regulação com esse objetivo incluem, segundo Ballington, Austin e Tjernstrom (2014): imposição de limites sobre doações, proibição de modalidades específicas de doação, adoção de cotas de gasto para candidatos e partidos, adoção de financiamento eleitoral público, e prestação de contas do financiamento eleitoral.

A prestação de contas consiste no requerimento de publicidade das informações sobre valores envolvidos na realização de campanhas eleitorais. O implemento dessa 
política tem dois objetivos: aumentar a transparência do financiamento eleitoral, e auxiliar instituições de regulação na adoção de políticas de controle do financiamento como a imposição de limites de doação.

O Brasil segue a tendência mundial de regulação pela adoção da prestação de contas. Segundo Schlickmann e Lubke (2008), a matéria foi disciplinada inicialmente pela Lei n. 4.740/1965. Porém, somente em 1993 a legislação foi efetiva no controle do financiamento. Nesse ano, a Lei n. 8.713/1993, inovou as normas para a administração financeira das campanhas eleitorais, estabeleceu a responsabilidade de partidos e candidatos, estipulou formas de obtenção e despesa de recursos e, finalmente, instruiu a elaboração da prestação de contas à Justiça Eleitoral.

A Lei n. 9.504/1997, que atualmente discrimina as normas eleitorais brasileiras obriga partidos políticos e candidatos a tornarem públicas informações contábeis relacionadas às suas campanhas. O inciso IV do artigo 28 da referida lei disciplina que: "Os partidos políticos, as coligações e os candidatos são obrigados, durante a campanha eleitoral, a divulgar, pela rede mundial de computadores (internet), nos dias 8 de agosto e 8 de setembro, relatório discriminando os recursos em dinheiro ou estimáveis em dinheiro que tenham recebido para financiamento da campanha eleitoral e os gastos que realizarem, em sitio criado pela Justiça Eleitoral para esse fim, exigindo-se a indicação dos nomes dos doadores e os respectivos valores doados somente na prestação de contas final de que tratam os incisos III e IV do art. 29 desta Lei."

O sítio usado pela Justiça Eleitoral para cumprimento da norma é o do TSE. Neste site é possível acessar uma base de dados chamada Repositório de Dados Eleitorais (RDE). O repositório é uma compilação de dados brutos das eleições com informações sobre o eleitorado, candidatos, prestação de contas e resultados das disputas eleitorais. Nele é possível consultar informações sobre as doações de campanha, incluindo o nome da empresa doadora, o montante doado, o candidato contemplado, seu estado e o cargo em disputa.

A Lei n. 9.504/1997 criou a oportunidade - por meio do RDE - de se analisar os impactos do financiamento eleitoral sobre vários aspectos do processo democrático brasileiro, dentre eles, a barganha entre financiadores e candidatos políticos. Autores como Claessens, Feijen e Laeven (2008), Boas, Hidalgo e Richardson (2014) e Arvate, Barbosa e Fuzitani (2013) buscam identificar os mecanismos relacionados a essa barganha estabelecendo relações entre o financiamento e compensações do governo. Este trabalho segue a linha desses pesquisadores averiguando o investimento governamental em ações como forma de compensação por contribuições para campanhas eleitorais. 


\section{Literatura}

A preocupação com a influência do dinheiro no processo democrático não é um fenômeno recente. Desde o século XIX, economistas como George (1883) escrevem sobre as consequências do financiamento eleitoral na democracia. O referido autor afirma que: "As eleições são o ponto inicial do nosso sistema político, destarte, enquanto as eleições forem vencidas pelo uso do dinheiro, e não for possível vencê-las sem ele, nenhuma precaução subsequente impedirá a corrupção."

O aumento da relevância política e a expansão do volume de recursos envolvidos em campanhas eleitorais fizeram com que a pesquisa relacionada ao tema crescesse. Esse crescimento ocorreu especialmente na década de 1980, quando a tendência mundial convergia no aumento da regulação do financiamento de campanhas eleitorais. Medidas como a prestação de contas e limitação de doações criaram bancos de dados que viabilizaram a expansão da pesquisa.

Os estudos empíricos desenvolvidos desde então apresentam conclusões que justificam o interesse de economistas e cientistas políticos em estudar o tema. A pesquisa comprovou que o financiamento eleitoral é capaz de influenciar pontos centrais relacionados à democracia como: o resultado das eleições e o direcionamento de políticas do governo. Em outras palavras, quem governa e como se governa.

Morton e Cameron (1992) fazem uma análise crítica da pesquisa relacionada ao financiamento eleitoral, sobretudo a que ocorreu na década de 80 e começo da década de 90, quando o interesse no tema crescia. Em seu artigo, os referidos autores sugerem alterações nos modelos usados para analisar o financiamento de campanhas eleitorais a fim de corrigir assunções que, na visão dos mesmos, não eram apropriadas para o contexto estudado.

Segundo Morton e Cameron (1992), a hipótese de que despesas de campanha influenciam resultados eleitorais caracteriza-se como um fato estilizado na literatura. Eles ressaltam essa como a questão mais investigada por pesquisadores da área de Financiamento Eleitoral. Outro fato estilizado citado pelos autores, e também largamente pesquisado na literatura, consiste na capacidade do financiamento eleitoral de influenciar políticas de gastos do governo. ${ }^{5}$

Estudos empíricos como Palda (1973) corroboram essas hipóteses mostrando que gastos envolvidos em campanhas afetam a probabilidade de eleição de candidatos. Usando

5 Os autores ainda citam como conclusões recorrentes da pesquisa o fato de que as contribuições de campanha têm pouco impacto perceptível em votações da esfera legislativa do governo - mas parecem afetar a votação de questões particularizadas, menos visíveis publicamente, tanto para fins ideológicos quanto para favorecimento de grupos de interesse. 
dados das eleições federais canadenses de 1966 e 1970 e estimações em OLS, o autor refuta a hipótese inicial de que a propaganda eleitoral não causaria efeitos sobre os resultados eleitorais. A evidência empírica aponta os gastos em propaganda eleitoral como uma variável com grande poder sobre os resultados do pleito eleitoral.

Outro trabalho que corrobora a hipótese de influência do financiamento no processo eleitoral por meio da mídia é Baek (2009). No trabalho desse autor o papel das instituições de comunicação e propaganda é analisado no contexto eleitoral, comparando dados entre 74 países. As evidências empíricas apontam que os sistemas de financiamento eleitoral mais flexíveis têm maior efeito sobre as probabilidades de eleição dos candidatos na medida em que a mídia é capaz de influenciar na decisão de voto por meio mecanismos como propaganda, tempo de televisão entre outros.

No que concerne a capacidade das regras eleitorais de influenciar políticas do governo, estudos como Besley e Case (1993) evidenciam a ocorrência desse tipo de influência por meio da análise do comportamento de candidatos à reeleição na presença de regras de prestação de contas eleitorais. Usando dados dos estados norte-americanos no período entre 1950 e 1986, os autores mostram que decisões de candidatos à reeleição relacionadas às escolhas sobre impostos, despesas, salários mínimos e outras compensações trabalhistas são afetadas de maneira significativa por regras de governabilidade ao final dos mandatos estaduais. ${ }^{6}$

Os exemplos ilustram a importância do financiamento eleitoral por meio da análise dos dois principais pontos pesquisados na área. Entretanto, além da capacidade de influenciar resultados das eleições e comportamento do governo eleito, o financiamento eleitoral é estudado sob vários outros aspectos visando à compreensão dos incentivos que orientam o comportamento de financiadores e candidatos, além das consequências da interação entre esses agentes.

Artigos como Hogan (2005) investigam os efeitos das regras de financiamento eleitoral sobre o comportamento estratégico de grupos de interesse em campanhas. $\mathrm{O}$ autor demostra que, em estados onde há limite para contribuições privadas, as empresas participam de forma mais ativa de outras modalidades de promoção de seus candidatos, como propaganda independente e doações para partidos.

Os resultados apresentados por Hogan (2005) mostram que os grupos de interesse ligados ao processo de financiamento eleitoral servem-se de uma grande variedade de técnicas eleitorais e que regras que impõem limites sobre doações eleitorais atuam como condicionantes para sua utilização. Dessa forma, tudo mais constante, o aumento da limitação do financiamento eleitoral parece aumentar a iniciativa de grupos de interesse em intervir diretamente no processo decisório de voto da sociedade.

$\overline{6}$ Outro trabalho que analisa a influência do financiamento eleitoral sobre as políticas governamentais é Bental e Ben-Zion (1975) 
Seguindo a linha de outros fatores pesquisados Campante (2011), por sua vez, analisa o impactos do financiamento eleitoral sobre a distribuição de renda da sociedade. Segundo o autor, se candidatos eleitos estão mais propensos a atender os interesses de grupos financiadores de suas campanhas, existe evidência para supor que o financiamento pode gerar desigualdade econômica, assumindo que agentes financiadores apresentam um nível de renda mais elevado que o cidadão médio.

A fim de endossar seu modelo micro-fundamentado, Campante (2011) apresenta evidências empíricas a partir de dados de contribuições de campanha das eleições presidenciais dos Estados Unidos. Os resultados mostram que a elevação da desigualdade de renda aumenta o volume de contribuições para o partido Republicano, mas não para o partido Democrata, conforme o autor prevê em seu modelo microeconômico.

A ampla gama de incentivos que orientam o comportamento de financiadores e candidatos, e os estudos que mapeiam esses aspectos mostram a importância da pesquisa do tema ao longo do tempo. O desenvolvimento dessa pesquisa aumentou gradualmente o arcabouço teórico implementado na modelagem desses incentivos envolvidos no financiamento eleitoral.

Em modelos largamente citados como Coate (2004), candidatos com mais recursos aumentam seu poder de divulgação e conquistam mais votos. Logo, esses agentes tentam maximizar o montante de contribuições para sua companha. Por outro lado, agentes financiadores desejam obter retorno por sua contribuição. Esse retorno consiste em benefícios que o candidato eleito pode proporcionar recorrendo à influência política de seu cargo.

No contexto brasileiro esse raciocínio é aplicável na medida em que, conforme Kinzo (2006), o conjunto de regras eleitorais não favorece o desenvolvimento da identificação partidária. Diferente de outros países, o Brasil possui diversas legendas sem relevância política, de modo que a ideologia partidária não exerce efeito significativo sobre a distribuição de votos. Assim, aumenta-se a responsabilidade do candidato buscar votos individualmente, e o potencial de influência do financiamento eleitoral eleva-se.

Adicionalmente, Claessens, Feijen e Laeven (2008) argumentam que o cenário brasileiro é favorável à análise do financiamento eleitoral principalmente em função do limitado nível de desenvolvimento das instituições. Os autores ressaltam que a grande participação governamental no mercado de crédito contribui para a ocorrência de influência política no Brasil. Baseados nessa visão, Claessens, Feijen e Laeven (2008) analisam a diferença entre o nível de crédito disponibilizado à empresas financiadoras e não financiadoras de campanhas.

Os autores analisam as eleições de 1998 e 2002 usando estimação do tipo efeitos fixos a fim de mitigar o efeito de características não observadas na decisão de disponibilização de crédito por parte de instituições governamentais - em especial, bancos de desenvolvimento. 
A análise desses autores se aproxima do exercício proposto neste trabalho na medida em que modela a decisão de investimento de agentes governamentais. A estratégia usada em Claessens, Feijen e Laeven (2008) também se aproxima desta proposta na medida em que são construídos grupos de tratamento e controle para identificação do efeito do financiamento eleitoral.

Além da análise de Claessens, Feijen e Laeven (2008), autores como Boas, Hidalgo e Richardson (2014) e Arvate, Barbosa e Fuzitani (2013) buscam identificar os mecanismos relacionados a compensação operada por candidatos e agentes financiadores de campanhas eleitorais no contexto brasileiro.

Arvate, Barbosa e Fuzitani (2013) investigam a hipótese de que empresas podem obter maior número de contratos públicos em função de doações para campanhas eleitorais. Isolando as eleições para Deputados Estaduais, os autores mostram que empresas doadoras recebem contratos de maior valor ao financiar campanhas de candidatos vencedores, candidatos de partidos tradicionais, e candidatos de partidos de esquerda. Os resultados mostram que o retorno esperado de doações é maior para candidatos de partidos tradicionais do que para candidatos de partidos de esquerda e para a média de todos os candidatos.

Boas, Hidalgo e Richardson (2014) empregam o método de Regressão Descontínua para identificar o efeito de uma vitória eleitoral sobre os contratos do governo com empresas doadoras e não doadoras. Os autores mostram que empresas especializadas em obras públicas podem esperar aumento substancial nos contratos quando candidatos a Deputado Federal do Partido dos Trabalhadores (PT) são financiados, e posteriormente, eleitos. Os resultados observados indicam que partidos como o PT priorizam políticas de gastos como forma de fortalecer sua posição política.

Seguindo a linha dessas análises, este trabalho investiga as eleições para Governador Estadual nos anos de 2002, 2006 e 2010 a fim de verificar se empresas doadoras de campanha recebem maior participação de instituições governamentais como sócios acionistas, após as eleições, devido à influência política de candidatos financiados.

Adicionalmente, propõe-se um exercício que extrapola a análise de um cargo em particular. Nesse exercício, são estudadas as doações para campanhas de todos os cargos eleitorais em disputa. Assim, prioriza-se o mapeamento de todos os recursos proveniente das empresas estudadas. O objetivo dessa configuração é assegurar que toda a influência política direcionada a compensar doações de campanha e beneficiar empresas doadoras esteja sendo capturada pelo modelo. 


\section{Dados}

A análise proposta exige dois conjuntos de informação. O primeiro consiste nos dados sobre o financiamento eleitoral. Esses foram obtidos junto ao Repositório de Dados Eleitorais (RDE), uma base de dados do Tribunal Superior Eleitoral, que discrimina as doações para campanhas eleitorais conforme a Lei 9.504/1997 e permite conhecer tanto o autor da doação de campanha quanto o candidato, comitê eleitoral ou partido político receptor. O segundo grupo de dados consiste nas informações financeiras das empresas estudadas. Essas informações foram obtidas junto a base de dados Economática.

As empresas estudadas consistem nas sociedades anônimas listadas na Bolsa de Valores de São Paulo. A lista de empresas que compõem a amostra usada em cada exercício e em cada ano analisado encontra-se no Apêndice C. Neste apêndice também é possível discernir as empresas que participaram do financiamento eleitoral daquelas que não fizeram doação nesse sentido.

A opção pela restrição da análise a essas empresas ocorre em função da disponibilidade de dados. Empresas de capital aberto incorrem na obrigação legal de divulgar suas informações contábeis e financeiras periodicamente para o mercado. Em contraponto, empresas que não estão listadas na bolsa de valores são eximidas dessa obrigação, logo seus dados financeiros não são abertos ao público, fato que inviabiliza sua análise.

\subsection{Dados Eleitorais}

No contexto brasileiro, existem duas formas de se fazer uma doação para um candidato eleitoral. Na primeira, que será chamada Doação Direta, o agente financiador transfere sua doação diretamente ao candidato de sua preferência. Na segunda forma de doação, que será chamada Doação Indireta, o financiador faz a doação para comitês eleitorais ou partidos políticos. Essas instituições, posteriormente, repassam o valor doado ao candidato de sua preferência. A Figura 1 ilustra as possíveis formas de doação.

O RDE contém as duas modalidades de doação aos candidatos eleitorais e está organizado em quatro bases de dados: Eleitorado, Resultados, Candidatos e Prestação de Contas. Esta última divide-se em três categorias: Candidatos, Comitês Eleitorais e Partidos Políticos. Cada uma dessas categorias é subdividida em Receitas e Despesas. A base Prestação de Contas está, portanto, dividida em seis sub-bases: Receita Candidato, Despesa Candidato, Receita Comitê, Despesa Comitê, Receita Partido e Despesa Partido. A Figura 2 ilustra a estrutura da base de Prestação de Contas do RDE.

Dentro dessa estrutura, a base Receita Candidato apresenta as Doações Diretas e 
Figura 1 - Diagramas de Doação

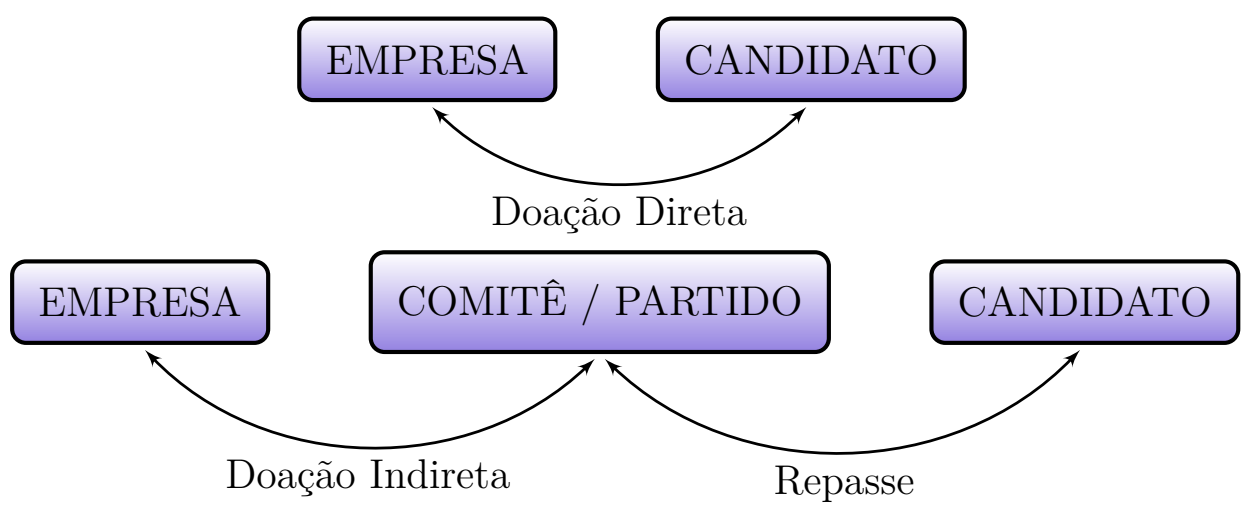

Fonte: elaboração própria com base nos dados do TSE

Figura 2 - Estrutura do Repositório de Dados Eleitorais

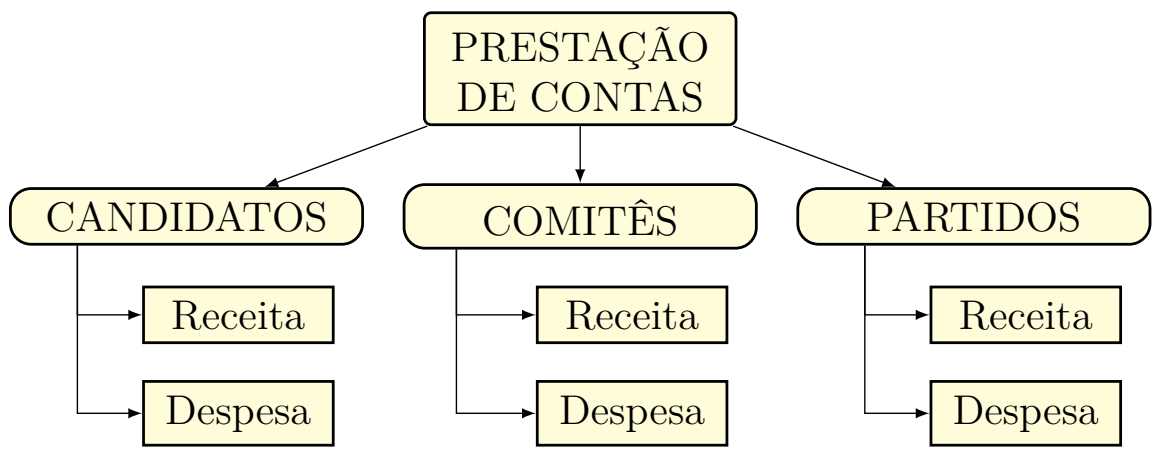

Fonte: elaboração própria com base nos dados do TSE

repasses de comitês e partidos aos candidatos eleitorais. Nela mapeia-se, portanto, todo o recurso apropriado por candidatos para realizar suas campanhas. As bases Receita Comitê e Receita Partido, por sua vez, mostram as doações de pessoas físicas e jurídicas para comitês eleitorais e partidos políticos, respectivamente. Logo, nessas bases mapeia-se todo o recurso passível de repasse por parte de comitês e partidos políticos aos candidatos eleitorais.

Devido à organização do RDE existe a possibilidade de dupla contagem dos recursos. A título de exemplo, doações feitas aos partidos políticos e comitês eleitorais, listadas nas bases Receita Partido e Receita Comitê, podem ser eventualmente repassadas aos candidatos, e assim constar também na base Receita Candidato, sendo, portanto, contabilizadas em mais de uma base.

Tendo em vista essa organização, não é possível determinar com acurácia o montante de recursos envolvidos no financiamento das eleições brasileiras. Se, por exemplo, soma-se os valores das bases de receita, corre-se o risco de dupla contagem. Se usa-se apenas as informações da base Receita Candidato, há risco de subestimar o valor envolvido no 
financiamento eleitoral, pois é impossível assegurar que doações para comitês e partidos tenham sido integralmente repassadas aos candidatos.

Em função disso, as estatísticas descritivas apresentadas neste trabalho reportam exclusivamente os valores apropriados pelos candidatos para realizar suas campanhas, qual seja, na base Receita Candidato. Ainda que esse procedimento não consiga precisar o volume de recursos envolvidos nas eleições, ele tem o mérito de proporcionar um panorama do contexto de financiamento eleitoral no Brasil e esclarecer alguns pontos.

Perguntas relativas ao montante de recursos envolvidos no financiamento eleitoral brasileiro, e quem são os agentes financiadores de campanhas eleitorais, podem ser compreendidas em maior grau por meio da análise descritiva dos dados eleitorais brasileiros. Nesse sentido, as informações das tabelas a seguir ajudam a esclarecer questões relacionadas ao financiamento eleitoral no Brasil, levantadas na introdução deste trabalho. Cabe ressaltar que nos dados do Tribunal Superior Eleitoral constam apenas doações de campanha devidamente registradas. Dessa forma, os dados refletem somente o financiamento de campanhas eleitorais que ocorre em conformidade com a lei. Assim, as informações apresentadas ignoram a existência de possíveis doações não registradas.

No que tange o restante da análise, o RDE possibilita obter com precisão o montante de recursos doados por empresas de capital aberto nas eleições. Para o Exercício Global foram usadas as doações de empresas abertas obtidas a partir da soma das doações constantes em cada uma das bases de receita. Para o Exercício Governador são feitas estimações das contribuições dessas empresas especificamente para candidatos a Governador Estadual conforme o Protocolo de Construção do Painel para Governadores constante no Apêndice A. Os valores apresentados nas tabelas foram inflacionados usando o Índice de Preços ao Consumidor Amplo (IPCA), calculado pelo IBGE. Os valores são ajustados usando o ano de 2014 como ano-base.

A Tabela 1 apresenta os montantes doados para campanhas segundo o cargo eleitoral em disputa, oferecendo informações sobre a magnitude do montante envolvido no financiamento de campanhas eleitorais no Brasil. Observa-se que, com exceção das eleições para Presidente e Senador em 2006, o valor do financiamento eleitoral brasileiro segue uma tendência crescente para todos os cargos eletivos em todas as eleições.

Os valores de contribuições para Presidente e Senador em 2006 na tabela são os únicos que fogem a esse padrão e parecem estar subestimados. Uma hipótese que explicaria esse fato é a participação predominante de recursos de partidos políticos e comitês eleitorais. Se essa hipótese for verdadeira, os recursos destinados a financiar as campanhas para Presidente e Senador em 2006 estariam predominantemente nas bases de Receita Comitê e Receita Partido, não constando na Tabela 1.

Observando os valores apresentados, chama à atenção a magnitude dos montantes 
Tabela 1 - Valor de Contribuições Eleitorais por Cargo

\begin{tabular}{|c|c|c|c|}
\hline & & Ano & \\
\hline & 2002 & 2006 & 2010 \\
\hline \multicolumn{4}{|l|}{ Cargo } \\
\hline Deputado Distrital & 11.073 .904 & 23.267 .862 & 31.281 .912 \\
\hline Deputado Estadual & 385.128 .476 & 602.868 .150 & 1.201 .854 .336 \\
\hline Deputado Federal & 350.136 .186 & 593.032 .423 & 1.199 .734 .353 \\
\hline Governador & 328.996 .105 & 436.210 .954 & 960.408 .388 \\
\hline Presidente & 38.683 .063 & 8.581 .960 & 355.252 .397 \\
\hline Senador & 130.796 .587 & 115.026 .568 & 460.285 .234 \\
\hline Total & 1.244 .814 .321 & 1.778 .987 .917 & 4.208.816.619 \\
\hline
\end{tabular}

Fonte: elaboração própria com base nos dados do TSE

envolvidos no financiamento eleitoral brasileiro no período. Levando em conta somente os valores constantes na base Receita Candidato, o valor médio de recursos envolvidos no financiamento de campanhas eleitorais considerando os três anos estudados corresponde a aproximadamente $\mathrm{R} \$ 2,41$ bilhões. No ano de 2010, o valor movimentado pelo financiamento eleitoral é de mais de $\mathrm{R} \$ 4,2$ bilhões.

A Tabela 2, por sua vez, apresenta as mesmas informações da Tabela 1 divididas pelo número de candidatos na disputa de cada cargo eletivo. Em outras palavras, a Tabela 2 apresenta o valor médio de contribuições recebidas por candidato segundo o cargo disputado. Esse valor pode ser interpretado como uma medida dos custos de uma campanha eleitoral no Brasil de acordo com o cargo eleitoral disputado.

Tabela 2 - Valor de Contribuições Eleitorais por Candidato

\begin{tabular}{lrrr}
\hline & \multicolumn{3}{c}{ Ano } \\
\hline & 2002 & 2006 & \multicolumn{2}{c}{ 2010 } \\
Cargo & & & \\
Deputado Distrital & 18.274 & 36.074 & 39.250 \\
Deputado Estadual & 34.724 & 52.689 & 101.956 \\
Deputado Federal & 83.845 & 120.144 & 246.049 \\
Governador & 1.713 .521 & 2.225 .566 & 6.445 .694 \\
Presidente & 6.447 .177 & 1.430 .327 & 39.472 .489 \\
Senador & 431.672 & 578.023 & 2.150 .866 \\
\hline
\end{tabular}

Fonte: elaboração própria com base nos dados do TSE

Obviamente, essa não é uma análise exaustiva já que essa medida desconsidera a heterogeneidade presente entre estados e candidatos. Em outras palavras, uma campanha ao cargo de Deputado Estadual pode ser mais custosa no Estado de São Paulo que no Estado de Tocantins, por exemplo. E esse fato não é capturado pelas médias apresentadas 
na Tabela 2. Ainda sim, nota-se uma relação direta entre o volume de gastos nas campanhas e o poder relativo de cada cargo envolvido.

Nesse sentido, campanhas para cargos com maior poder político envolvem maiores gastos de campanha. O único ano que foge a esse padrão é 2006 com campanhas para governador mais caras que campanhas presidenciais, porém, mais uma vez, isso pode ser fruto da organização dos dados eleitorais. Nas médias de valores gastos por candidato em suas campanhas, destacam-se os valores envolvidos no financiamento das campanhas presidenciais de 2010, com gastos próximos a $\mathrm{R} \$ 40$ milhões por candidato.

A Tabela 3, por sua vez, decompõe o volume de recursos envolvidos no Financiamento Eleitoral segundo a fonte da doação. A partir das informações dessa tabela é possível determinar a composição dos agentes que financiam as campanhas eleitorais no Brasil. Nota-se que as doações de pessoas jurídicas desempenham papel de grande relevância no financiamento eleitoral brasileiro, conforme mostra a Tabela 4. A participação de empresas no volume de recursos doados corresponde, em média, a aproximadamente $47 \%$ dos recursos totais nos anos estudados.

Tabela 3 - Valor de Contribuições por Fonte de Recurso

\begin{tabular}{lrrr}
\hline & \multicolumn{3}{c}{ Ano } \\
\hline & 2002 & 2006 & 2010 \\
Fonte de Recurso & & & \\
Comercialização de bens ou realização de eventos & 20.898 .638 & 25.927 .419 & 29.287 .537 \\
Doações pela Internet & - & - & 236.053 \\
Recursos de origens não identificadas & 1.106 .210 & 544.446 & 660.404 \\
Recursos de outros candidatos/comitês & 77.664 .544 & 176.329 .018 & 1.127 .972 .657 \\
Recursos de partido político & 57.852 .555 & 22.197 .137 & 701.708 .194 \\
Recursos de pessoas físicas & 415.010 .739 & 301.279 .230 & 463.218 .133 \\
Recursos de pessoas jurídicas & 672.129 .210 & 949.740 .118 & 1.453 .306 .773 \\
Recursos próprios & - & 302.959 .616 & 432.406 .642 \\
Rendimentos de aplicações financeiras & 152.425 & 10.933 & 20.224 \\
& & & \\
Total & 1.244 .814 .321 & 1.778 .987 .917 & 4.208 .816 .619 \\
\hline
\end{tabular}

Fonte: elaboração própria com base nos dados do TSE

Além do papel das empresas como principais fontes de recursos de campanhas eleitorais, também se destaca o papel das pessoas físicas nessa função. A partir dos dados da Tabela 3, nota-se que pessoas físicas têm, em média, uma participação de aproximadamente $20 \%$ no volume de recursos destinados ao financiamento de campanhas nos anos estudados.

Por meio das informações apresentadas nas Tabelas 3 e 4 é possível observar o papel altamente relevante desempenhado pelas empresas no financiamento eleitoral brasileiro no período estudado. Porém, é necessário investigar o papel desempenhado especificamente por empresas de capital aberto nesse contexto, tendo em vista o fato de ser esta a população analisada neste trabalho. 
Tabela 4 - Porcentagem do Financiamento Eleitoral de Empresas

\begin{tabular}{cccc}
\hline Ano & Doações de Empresas & Total Movimentado & Porcentagem \\
\hline 2002 & 672.129 .210 & 1.244 .814 .321 & $54 \%$ \\
2006 & 949.740 .118 & 1.778 .987 .917 & $53 \%$ \\
2010 & 1.453 .306 .773 & 4.208 .816 .619 & $35 \%$ \\
\hline
\end{tabular}

Fonte: elaboração própria com base nos dados do TSE

Essa função é desempenhada pela Tabela 5 que ilustra a participação das empresas abertas no financiamento eleitoral. Nota-se que as sociedades anônimas, embora correspondam a menos de um por cento do número de empresas envolvidas no financiamento de campanhas, são responsáveis, em média, por aproximadamente dez por cento do valor doado por empresas. Em outras palavras, um número muito pequeno de sociedades anônimas é responsável por uma fração significativa do financiamento de campanhas. A partir dessas informações supõe-se que as sociedades anônimas realizaram doações relativamente maiores no período estudado, desempenhando papel de grande importância no financiamento de campanhas.

Tabela 5 - Empresas de Capital Aberto no Financiamento Eleitoral

\begin{tabular}{cccc}
\hline Ano & $\mathbf{N}^{\text {o de Empresas Doadoras }}$ & $\mathbf{N}^{\text {o }}$ de Empresas Bovespa Doadoras & Porcentagem \\
\hline 2002 & 12457 & 116 & $0,93 \%$ \\
2006 & 17130 & 110 & $0,64 \%$ \\
2010 & 18331 & 97 & $0,53 \%$ \\
\hline Ano & Valor de Doação Empresas & Valor de Doação Empresas Bovespa & Porcentagem \\
2002 & 366.282 .948 & 43.261 .537 & $12 \%$ \\
2006 & 640.072 .865 & 60.632 .422 & $9 \%$ \\
2010 & 1.113 .048 .000 & 88.018 .506 & $8 \%$ \\
\hline
\end{tabular}

Fonte: elaboração própria com base nos dados do TSE

Tendo ciência da importância do papel desempenhado por empresas no financiamento eleitoral brasileiro, é interessante saber como se distribuem as doações desses agentes. A Figura 3, 4 e 5 mostra a distribuição das doações de empresas em cada ano estudado. Nos gráficos de 2002 e 2006, nota-se uma distribuição logarítmica das doações, na qual muitas empresas efetuam doações de menor valor, enquanto algumas empresas doam valores substancialmente maiores. Esse padrão se repete de forma ainda mais acentuada no ano de 2010. A partir da interpretação dos dados da Tabela 5, supõe-se que as doações de empresas de capital aberto figuram na cauda das distribuições apresentadas na Figura ??, sendo substancialmente maiores que a média das doações de pessoas jurídicas. 
Figura 3 - Distribuição do Valor das Doações 2002

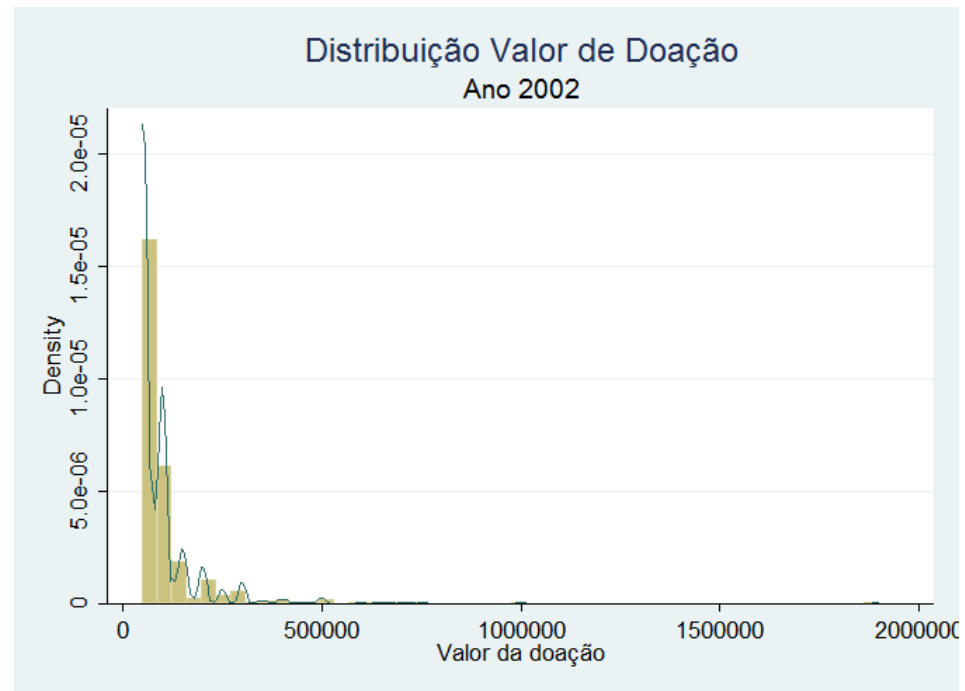

Fonte: elaboração própria com base nos dados do TSE

Figura 4 - Distribuição do Valor das Doações 2006

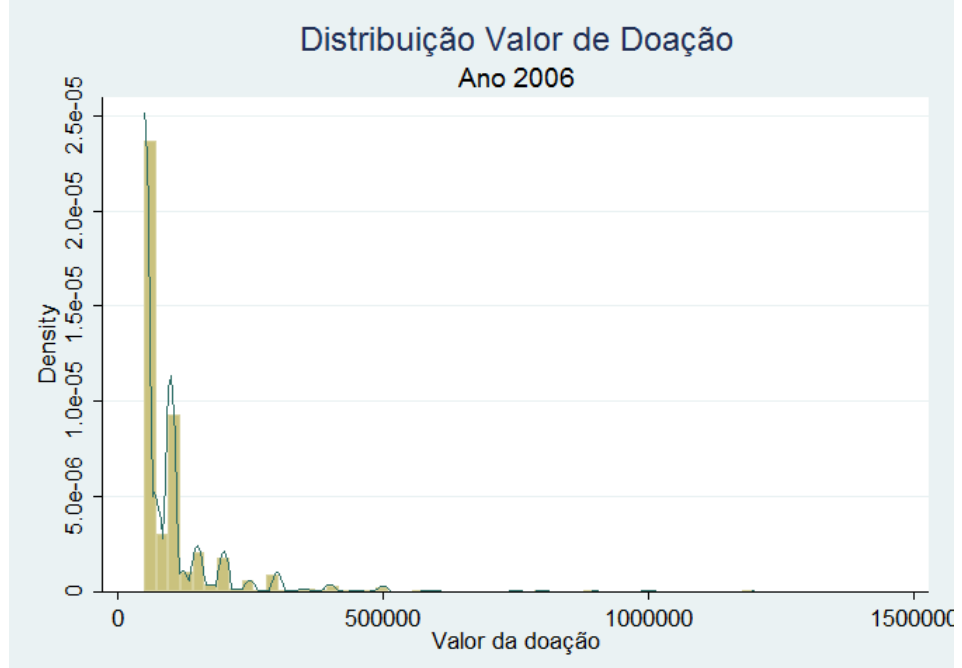

Fonte: elaboração própria com base nos dados do TSE

\subsection{Dados Financeiros}

Os dados financeiros das empresas de capital aberto desempenham duas funções na análise. A uma, esses dados serão usados no modelo como variáveis de controle. A duas, esses dados servem como base para a construção da variável dependente em análise - a participação do governo como acionista de sociedades anônimas brasileiras.

As variáveis usadas como controle são apresentadas na Tabela 6. A escolha dessas variáveis baseia-se no modelo elaborado por Claessens, Feijen e Laeven (2008) para verificar o efeito do financiamento eleitoral sobre o volume de crédito oferecido por bancos à pessoas jurídicas. Adicionalmente, Lazzarini et al. (2015) utilizam variáveis semelhantes para controlar a decisão de investimento de bancos de desenvolvimento em empresas. Ambos os 
Figura 5 - Distribuição do Valor das Doações 2010

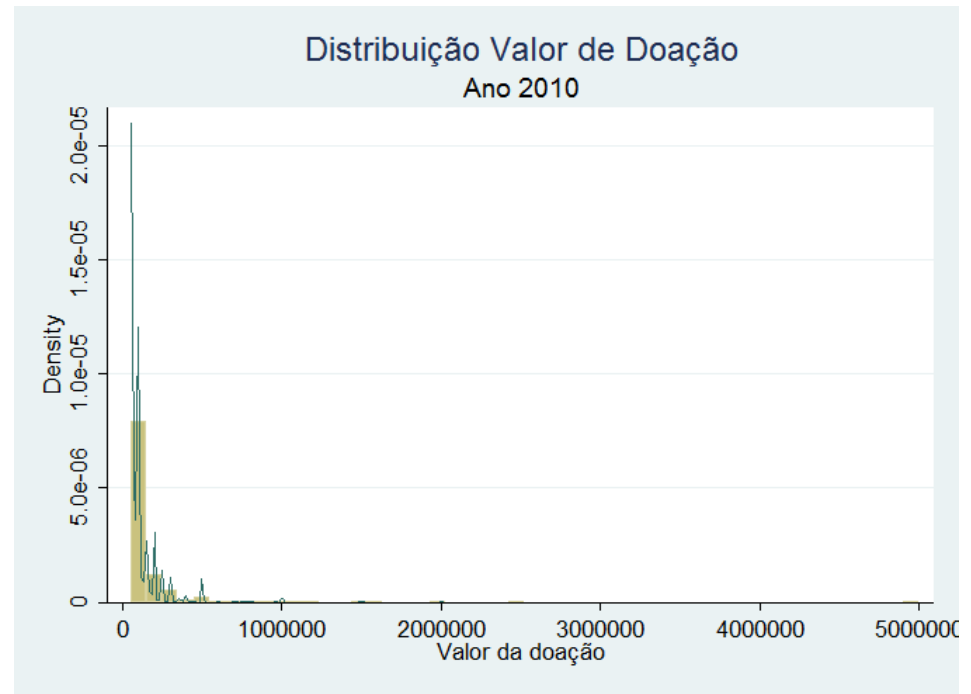

Fonte: elaboração própria com base nos dados do TSE

trabalhos modelam decisões de investimento de agentes governamentais e nesse sentido se aproximam da proposta de análise formulada neste trabalho.

Tabela 6 - Variáveis Financeiras de Controle

\begin{tabular}{cllc}
\hline Variável & Nome & Detalhes & Fonte \\
\hline $\ln A t T$ & Logaritmo do Ativo Total & - & Economática \\
ML & Margem Líquida & Últimos 12 meses & Economática \\
Ret & Retorno/Ativo Total & Fechamento anual & Economática \\
DLPL & Dívida Líquida/Patrimônio Líquido & - & Economática \\
ME & Margem EBIT & Últimos 12 meses & Economática \\
ROIC & ROIC/Ativo Total & Porcentagem no últimos 12 meses & Economática \\
Capex & Capex/Ativo Total & Últimos 12 meses & Economática \\
\hline
\end{tabular}

Fonte: elaboração própria com base nos dados da Economática

Claessens, Feijen e Laeven (2008) usam oito indicadores financeiros para controlar a decisão de disponibilização de crédito à empresas por parte de bancos ligados ao governo. Esses indicadores são: Logaritmo do Ativo Total, Ativos Fixos/Ativo Total, Passivo/Ativo Total, EBIT, Crescimento de Vendas, Dívidas Bancárias Totais, Dívidas Bancárias de Curto Prazo e Dívidas Bancárias de Longo Prazo. Segundo os autores, essas variáveis são regularmente usadas em análises de desempenho de empresas abertas.

Aqui serão utilizados: Logaritmo Ativo Total e EBIT conforme Claessens, Feijen e Laeven (2008). Capex (Capital Expenditure) e Roic (Return On Invested Capital), normalizadas pelo Ativo Total, são usadas como proxy para as medidas de Ativos Fixos e Passivo. Para Crescimento de Vendas, a Margem de Lucro Líquida é usada como proxy. Por fim, a variável Retorno é acrescida ao modelo em função da importância atrelada às variáveis relacionadas ao lucro da organização. As três variáveis de dívida são excluídas do modelo por apresentarem alto nível de correlação com outros regressores. 
Além dessas variáveis de controle, também são incluídas dummies de ano ao modelo a fim de controlar efeitos de eventos exógenos que possam ter ocorrido em anos específicos dentro do período analisado.

\subsection{Variável Dependente}

A escolha da variável por meio da qual se acredita - e eventualmente testa-se - que a influência política se manifesta é fundamental nas análises de financiamento eleitoral. Boas, Hidalgo e Richardson (2014) argumentam que estudos na área apresentam problemas de endogeneidade em função de correlação das variáveis dependentes escolhidas - aquelas sobre as quais acredita-se que o financiamento eleitoral tenha efeitos - com questões ideológicas inerentes ao contexto político em que o financiamento eleitoral se insere. O número de votos de legisladores a leis que favorecem grupos de interesse é, segundo Boas, Hidalgo e Richardson (2014), um exemplo de variável com esse problema.

Outras variáveis dependentes são afetadas por inúmeros parâmetros exógenos que dificultam a estimação do efeito da influência política. O preço de ações de empresas é um exemplo desse tipo de variável. Em estudos como Claessens, Feijen e Laeven (2008), onde os autores também usam o preço das ações como variável dependente, há dificuldade em se diferenciar os efeitos da influência política que visa recompensar o financiamento de campanhas das expectativas de agentes do mercado financeiro de que essa influência se manifeste.

Além dessas considerações, Morton e Cameron (1992) argumentam que certas medidas geradas pela influência política de candidatos eleitos não geram vantagens somente para as empresas doadoras e portanto não podem ser consideradas ações que visam compensar o financiamento de campanhas eleitorais. Isso ocorre porque, em muitos casos, os impactos da influência política englobam mercados e setores inteiros. Isenções fiscais, por exemplo, são medidas que demandam alterações em leis que englobam todas as empresas de um setor produtivo, financiadoras de campanhas ou não. Dessa maneira, essa é uma medida que não poder ser usada como variável dependente em uma análise do impacto do financiamento eleitoral.

Em suma, é preciso escolher uma variável - por meio da qual se manifesta a influência política que visa recompensar o financiamento eleitoral - que diferencie empresas doadoras e não doadoras, gerando vantagens somente para as primeiras. Nesse sentido, a variável dependente escolhida neste trabalho corresponde à porcentagem de participação do governo na composição acionária das empresas listadas na Bolsa de Valores de São Paulo. Essa variável atende o requisito anteriormente discutido, na medida em que se assume que candidatos eleitos podem exercer influência a fim de que agentes governamentais comprem ações especificamente daquelas empresas que financiaram suas campanhas. 
É verdade que essas ações, na maioria dos casos, são negociadas no mercado financeiro secundário. Em outras palavras, a empresa não recebe aportes do governo quando estes compram suas ações no mercado. Entretanto, se considera-se o preço das ações de uma empresa como uma proxy da eficácia de sua gestão, para citar um exemplo, a compra de ações por parte do governo pode aumentar o valor da empresa no mercado, gerando vantagens competitivas para as mesmas.

Assim, neste trabalho pretende-se usar a participação do governo como acionista das empresas listadas na Bolsa de Valores de São Paulo como variável dependente a fim de descobrir se essa é uma das maneiras pelas quais ocorre a compensação do financiamento de campanhas eleitorais no Brasil. Essa variável foi construída por meio de dados de composição acionária da Economática que mostram os acionistas das empresas listadas na Bovespa e suas respectivas participações no capital de acordo com o ano pesquisado.

Dentro dos quadros de composição acionária, os acionistas de cada empresa são classificados como privados ou agentes governamentais. A partir dessa classificação, a variável dependente é construída isolando e somando as participações dos agentes governamentais no capital das empresas em cada ano. A soma das participações é interpretada como o investimento do governo em ações da empresa naquele ano e será chamada ShareGov.

A classificação dos acionistas exerce grande importância sobre os resultados da análise proposta na medida em que determina os valores da participação do governo como acionista das sociedades anônimas. O objetivo da classificação é isolar acionistas sobre os quais se acredita que a influência de integrantes do governo se manifesta. Sob a validade desse pressuposto é possível verificar a hipótese de que candidatos eleitos usam sua influência para induzir agentes governamentais a investir em ações de empresas que participam do financiamento eleitoral.

Para minimizar o grau de discricionariedade presente na classificação dos acionistas, criou-se uma regra baseada na legislação orçamentária brasileira. A Constituição Federal de 1988 determina que o Poder Executivo estabeleça anualmente leis de orçamento. As Leis de Orçamento Anuais da União e dos Estados contém orçamentos de investimento das empresas em que o estado, direta ou indiretamente, detenha a maioria do capital social com direito a voto. ${ }^{7}$

A regra de classificação dos acionistas consiste na observação desses orçamentos em cada ano de eleição para definição daqueles que serão interpretados como governo. Em outras palavras, assume-se que o governo exerce influência política sobre as empresas nas quais detenha a maioria do capital social com direito a voto. Dessa forma, foram consideradas agentes do governo as instituições que constam nos Orçamento de Investimento das Empresas Estatais das Leis de Diretrizes Orçamentárias Federais e Estudais para cada

7 O Orçamento de Investimento das Empresas Estatais (OI) compreende os investimentos das empresas controladas pelo estado. 
um dos anos eleitorais analisados. Após a classificação a variável dependente (ShareGov) é obtida somando-se a participação dos agentes nas empresas de capital aberto.

A Tabela 7 mostra a série histórica da média de participação do governo no quadro acionário das empresas Bovespa. A partir das informações dessa tabela, nota-se que a participação média do governo brasileiro como acionista de empresas abertas apresenta tendência decrescente. No intervalo entre 1995 e 1999, o governo era dono, em média de 20,79\% das ações de empresas listadas na Bolsa, na década de 2000 essa taxa caiu para $17,46 \%$, enquanto no período entre 2010 e 2015 essa taxa caiu para 12,79\%.

Tabela 7 - Participação do Governo na Composição Acionária das Empresas Bovespa

\begin{tabular}{cccc}
\hline Ano & ShareGov & Ano & ShareGov \\
\hline $\mathbf{1 9 9 5}$ & 26,24 & $\mathbf{2 0 0 6}$ & 17,95 \\
$\mathbf{1 9 9 6}$ & 17,17 & $\mathbf{2 0 0 7}$ & 15,78 \\
$\mathbf{1 9 9 7}$ & 19,37 & $\mathbf{2 0 0 8}$ & 15,69 \\
$\mathbf{1 9 9 8}$ & 20,90 & $\mathbf{2 0 0 9}$ & 14,56 \\
$\mathbf{1 9 9 9}$ & 20,28 & $\mathbf{2 0 1 0}$ & 14,80 \\
$\mathbf{2 0 0 0}$ & 22,20 & $\mathbf{2 0 1 1}$ & 13,32 \\
$\mathbf{2 0 0 1}$ & 21,70 & $\mathbf{2 0 1 2}$ & 12,55 \\
$\mathbf{2 0 0 2}$ & 22,17 & $\mathbf{2 0 1 3}$ & 12,11 \\
$\mathbf{2 0 0 3}$ & 21,56 & $\mathbf{2 0 1 4}$ & 12,51 \\
$\mathbf{2 0 0 4}$ & 23,03 & $\mathbf{2 0 1 5}$ & 11,50 \\
\hline
\end{tabular}

Fonte: elaboração própria com base nos dados da Economática

\subsection{Amostragem}

Tabela 8 - Diferenças em Diferenças

\begin{tabular}{|c|c|c|c|}
\hline & \multicolumn{3}{|c|}{ Número de Empresas - Exercício Global } \\
\hline & Doadoras & Não Doadoras & Total \\
\hline 2002 & 40 & 62 & 102 \\
\hline 2006 & 33 & 50 & 83 \\
\hline \multirow[t]{3}{*}{2010} & 62 & 92 & 154 \\
\hline & Número de & Empresas - Exercí & Yovernador \\
\hline & Doadoras & Não Doadoras & Total \\
\hline 2002 & 25 & 81 & 106 \\
\hline 2006 & 22 & 60 & 82 \\
\hline 2010 & 38 & 115 & 153 \\
\hline
\end{tabular}

Os dados da Economática trazem informações de 430 empresas com ações comercializadas na Bolsa de Valores de São Paulo. Entretanto a amostragem restringe a análise às 
empresas que possuem informação para todas as variáveis financeiras usadas no modelo, além da variável dependente, em pelo menos seis dos oito anos analisados em cada janela temporal analisada neste trabalho. Em função disso, várias empresas foram retiradas da amostra.

A Tabela 8 exibe o número de empresas usadas em cada exercício assim como a composição dos grupos de doadoras (grupo de tratados) e não doadoras (grupo de controle). A partir das informações da Tabela 8 nota-se que, em média, aproximadamente $73 \%$ das empresas presentes na base Economática foram retiradas das amostras estudadas em cada exercício. A lista de empresas que compõem a amostra usada em cada exercício em cada ano analisado encontra-se no Apêndice C. 


\section{Metodologia}

Para avaliar o efeito do financiamento eleitoral sobre a decisão de compra de ações por parte do governo será usada a metodologia de Diferenças em Diferenças. Essa metodologia foi introduzida por Ashenfelter e Card (1984) e desde então vem sendo largamente usada para inferência de efeito causal em Econometria. ${ }^{8}$

O método de Diferenças em Diferenças consiste na comparação de uma variável de interesse entre dois grupos distintos, durante dois períodos de tempo. No primeiro período, não há tratamento. No segundo período, um dos grupos é tratado. O impacto do tratamento consiste na diferença calculada sobre a variável de interesse entre os grupos, antes e depois do tratamento. Contudo, esse impacto pode derivar de outras variáveis que oscilam no tempo, que não o tratamento. Por isso, o método de Diferenças em Diferenças usa variáveis de controle para isolar o efeito do tratamento investigado sobre a variável de interesse.

O principal pressuposto para o uso dessa metodologia consiste na suposição de que o grupo de controle representa um bom contrafactual para o grupo de tratamento. Isso ocorre quando o grupo de controle representa o que ocorreria com o grupo tratado caso não houvesse tratamento. Esse é um pressuposto não testável, mas válido quando trajetórias pré-tratamento da variável dependente são similares entre os grupos.

O método assume que desvios da variável dependente entre os grupos após o tratamento são atribuíveis aos efeitos causais do tratamento. Para que essa metodologia alcance resultados robustos é preciso que a composição dos grupos não se altere de forma significativa entre os períodos estudados. Além disso, os grupos não podem ser afetados de forma heterogênea por mudanças exógenas após o tratamento. A forma como o problema analisado se enquadra na metodologia proposta e suas hipóteses principais são apresentadas a seguir.

\subsection{Estratégia Empírica}

A estratégia para identificar o efeito do financiamento eleitoral sobre a compra de ações por parte do governo consiste em avaliar empresas de capital aberto em dois momentos distintos: antes e após o pleito eleitoral. Essas empresas são divididas em dois grupos: doadoras de campanhas eleitorais e não doadoras. As empresas de capital aberto que participaram do financiamento de campanhas constituem o grupo de tratamento em análise enquanto as empresas que não contribuíram nesse sentido constituem o grupo de

\footnotetext{
8 O trabalho de Card e Krueger (1994) tem grande relevância na disseminação dessa metodologia.
} 
controle. Desse modo, o tratamento consiste na participação da empresa no financiamento eleitoral.

O período temporal em análise consiste no ciclo eleitoral no qual as empresas estudadas participam do financiamento eleitoral. Logo, essas serão analisadas nos quatro anos antes das eleições e os quatro anos posteriores ao pleito. Para a eleição de 2002, por exemplo, analisa-se o período compreendido entre 1999 e 2006, onde o intervalo entre 1999 e 2002 consiste no período pré-tratamento e o intervalo entre 2003 e 2006 no período pós-tratamento.

Assume-se, portanto, que os benefícios que o governo pode gerar para empresas doadoras ocorrem durante o mandato desse governo. Em função dessa suposição, empresas tratadas em um ciclo eleitoral não podem ser classificadas como controle no ciclo imediatamente posterior, pois ainda estariam sofrendo a influência política do primeiro ciclo. Essas empresas foram retiradas da amostra. Essa estratégia é implementada em dois exercícios complementares.

O primeiro deles, denominado Exercício Global, contempla doações para todos os cargos eletivos disputados. A vantagem desse procedimento consiste na garantia de que toda a influência política direcionada a compensar eventuais doações de campanha está sendo capturada pelo modelo. A desvantagem dessa configuração consiste na dispersão da influência política quando se analisa conjuntamente todos os cargos em disputa. Essa dispersão enfraquece a hipótese de que a influência política acontece por meio das instituições classificadas como governo dentro dos quadros de composição acionária das empresas. Isso ocorre porque a influência de certos cargos - como Deputado Distrital - tem menor probabilidade de se desenvolver por meio dessas instituições.

O segundo exercício, por sua vez, denominado Exercício Governador, restringe-se à eleição para o cargo de Governador Estadual. Os dados eleitorais do TSE são manipulados conforme o Protocolo de Construção do Painel para Governadores - constante no Apêndice A - a fim de produzir estimativas das doações de empresas abertas para candidatos aos governos das unidades federativas do Brasil.

A desvantagem dessa configuração consiste no uso de estimativas das doações realizadas por sociedades anônimas. Nesse exercício, não é possível garantir que os valores usados correspondem, de fato, aos recursos apropriados pelos candidatos para realizar suas campanhas. A vantagem dessa configuração consiste na restrição da influência política a um cargo político que por hipótese tem exerce maior influencia sobre as entidades políticas classificadas como governo na construção da variável dependente.

Os exercícios se complementam na medida em que seus pontos fortes e fracos se compensam. A análise global das eleições apresenta maior acurácia no mapeamento de recursos enquanto a análise de governadores permite restringir os canais de influência 
a um cargo que presumidamente tem maior grau de envolvimento com as instituições classificadas como governo.

\subsection{Modelo}

Conforme Card e Krueger (1994) o modelo a ser estimado consiste na seguinte função:

$$
Y_{i t}=\alpha X_{i t}+\delta T_{i t}+\theta D_{i t}+\beta\left(T_{i t} D_{i t}\right)+\epsilon_{i t}
$$

Em que $Y$ representa a variável dependente - ShareGov, $i$ representa cada empresa na amostra, $t$ corresponde ao indicador temporal, $X$ representa as covariadas de controle, que incluem as variáveis financeiras e dummies para os anos da janela analisada, $T$ representa a dummy de tratamento, $D$ representa a dummy de intervenção temporal e $\epsilon$ corresponde ao erro. O parâmetro de diferenças em diferenças - correspondente a $\beta$ mede a variação da porcentagem de participação do governo em ações entre os grupos de tratamento e controle. Seguindo a metodologia adotada, o modelo proposto é construído observando-se as seguintes hipóteses:

Hipótese 1: A tendência temporal da variável dependente pré-tratamento é similar entre os grupos, podendo variar em nivel. As figuras a seguir apresentam a trajetória da média de participação do governo no capital de sociedades anônimas para os grupos de tratamento e controle nos quatro anos antes da eleição e nos quatro anos posteriores, nos dois exercícios propostos. Nota-se que a trajetória da variável dependente pré-tratamento apresenta padrões similares entre os grupos nos anos analisados.

Figura 6 - Trajetórias de ShareGov por Eleição - Exercício Global 2002

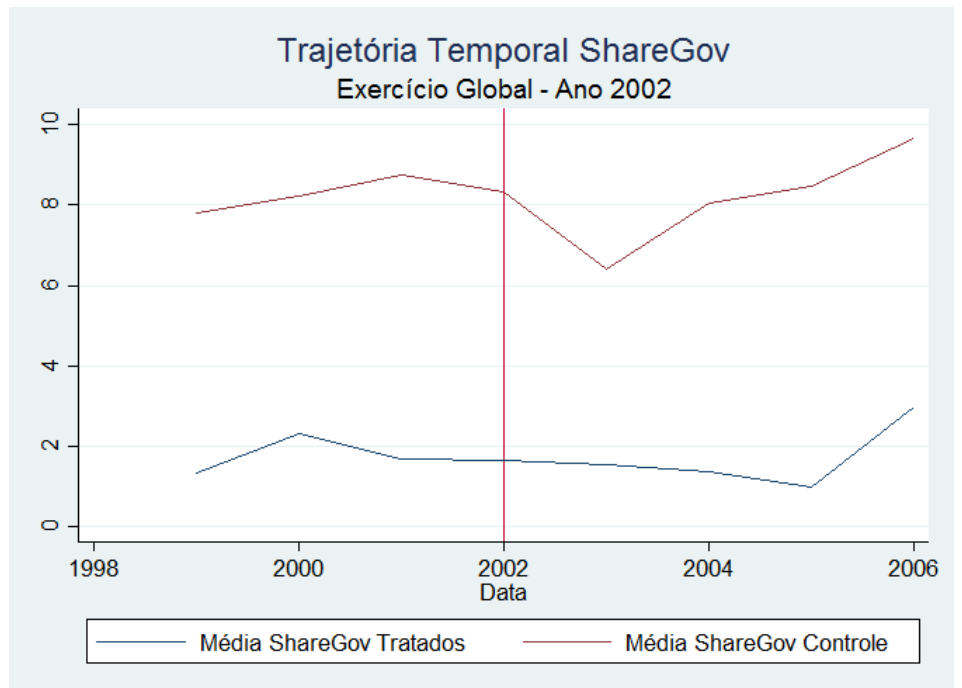

Fonte: elaboração própria com base nos dados da Economática 
Figura 7 - Trajetórias de ShareGov por Eleição - Exercício Global 2006

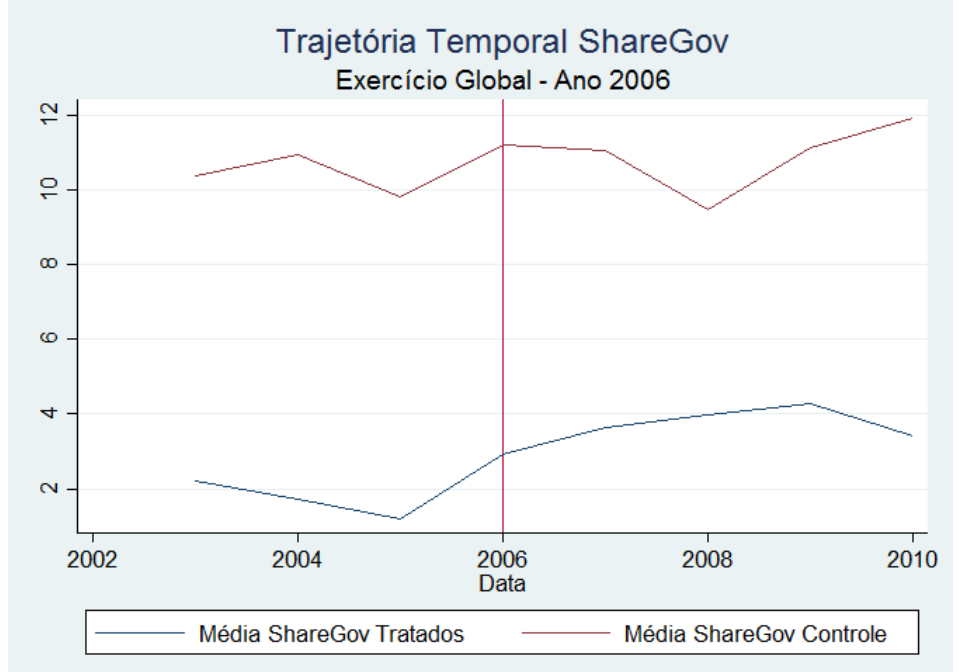

Fonte: elaboração própria com base nos dados da Economática

Figura 8 - Trajetórias de ShareGov por Eleição - Exercício Global 2010

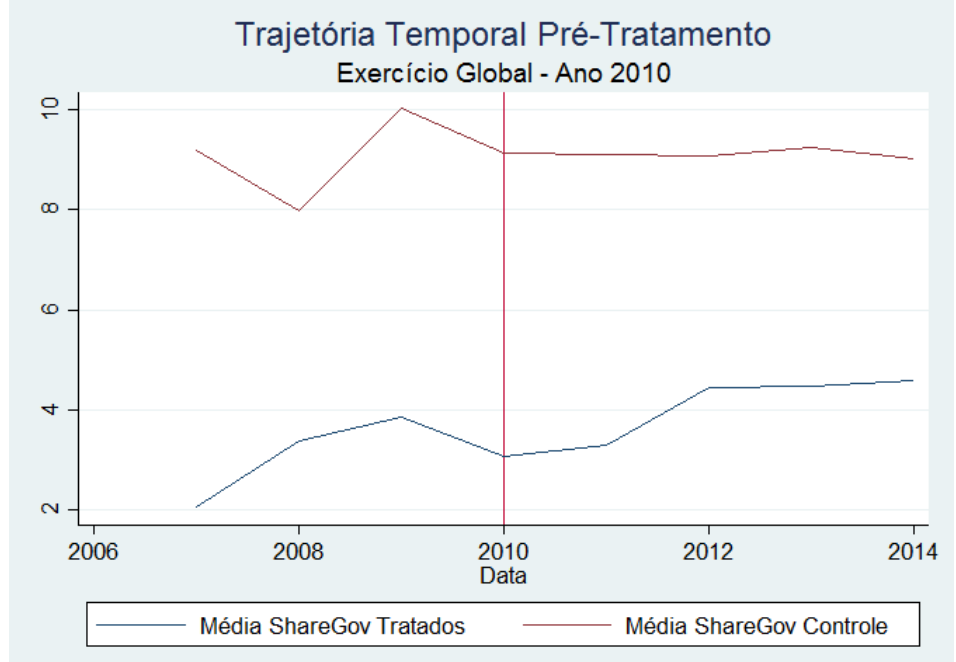

Fonte: elaboração própria com base nos dados da Economática

Hipótese 2: Os benefícios oferecidos à empresas doadoras advindos da influência política de candidatos eleitos ocorrem durante o mandato do governo eleito. Assume-se que os governantes exercem a influência política de seus cargos no período para o qual foram eleitos. Adicionalmente assume-se que o efeito da influência política não perdura no tempo, tendo em vista a constante renovação dos atores envolvidos no financiamento de campanhas a cada novo ciclo eleitoral.

Hipótese 3: A composição dos grupos de tratamento e controle não se altera de forma significativa entre os períodos estudados. Essa hipótese é atendida em função da forma como o problema analisado foi montado. A classificação das empresas em tratamento e controle depende de sua participação no financiamento eleitoral antes da eleição. Desse modo, depois da eleição não há alteração na composição dos grupos. 
Figura 9 - Trajetórias de ShareGov por Eleição - Exercício Governado 2002

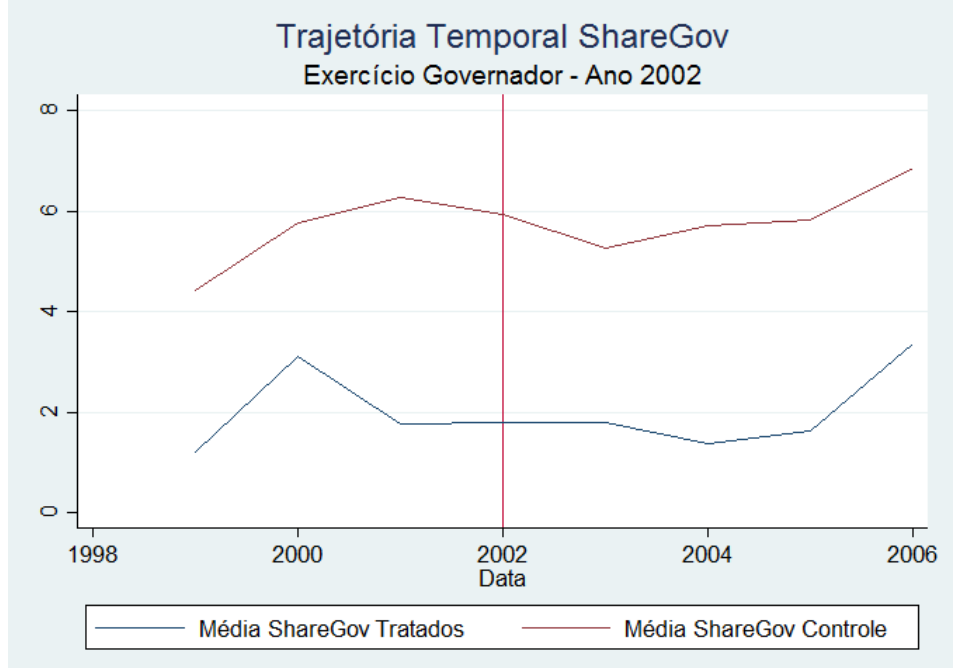

Fonte: elaboração própria com base nos dados da Economática

Figura 10 - Trajetórias de ShareGov por Eleição - Exercício Governador 2006

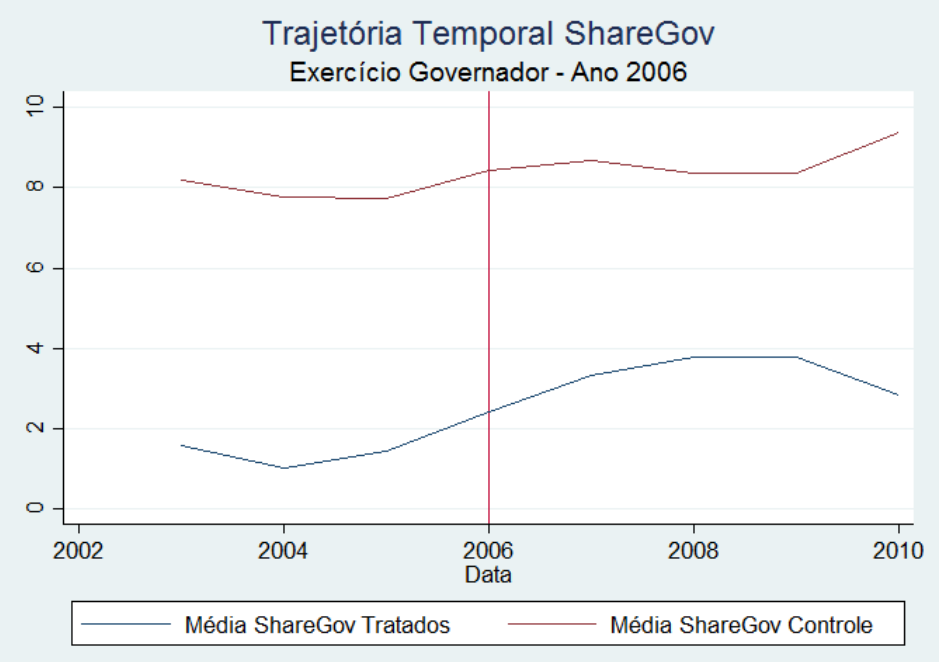

Fonte: elaboração própria com base nos dados da Economática

Hipótese 4: Os grupos não são afetados de forma heterogênea por mudanças exógenas após o tratamento. Essa é uma hipótese difícil de ser testada. Devido ao alto grau de complexidade inerente ao ambiente socioeconômico, é impossível garantir que as empresas sejam afetadas de maneira semelhante por eventos exógenos de qualquer natureza. Dessa maneira, essa hipótese certamente enfraquece o modelo e seus resultados. Contudo, dentro do contexto da hipótese que se discute, é conveniente analisar a distribuição setorial das empresas estudadas dentro dos respectivos grupos de tratamento e controle.

Se a composição de setores de mercado entre os grupos for altamente desequilibrada as mudanças exógenas que ocorrem no ambiente econômico podem ter efeitos fortemente heterogêneos entre os grupos. Além disso, o governo pode decidir investir em setores diferentes em função de outros fatores conjunturais que não o financiamento eleitoral 
Figura 11 - Trajetórias de ShareGov por Eleição - Exercício Governador 2010

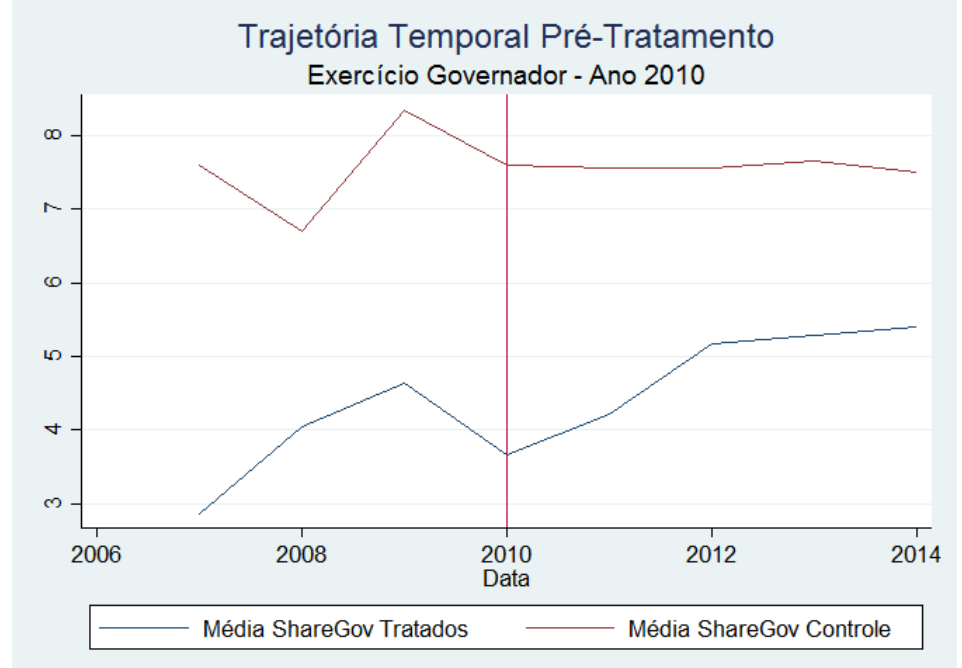

Fonte: elaboração própria com base nos dados da Economática

realizado por empresas específicas.

Para que esses problemas tenham seu efeito atenuado sobre o modelo e seus resultados é desejável que a composição setorial das empresas seja semelhante para os grupos de tratamento e controle. Ainda que esse fato não garanta o atendimento da hipótese discutida, sua observância poder contribuir em alguma medida para a confiabilidade dos resultados. Nesse sentido, a Tabela 9 mostra a composição de setores de mercado de cada grupo estudado para o Exercício Global. Por sua vez, a Tabela 10 apresenta as mesmas informações para o Exercício Governador. Percebe-se que a composição setorial entre os grupos é, em certa medida, equilibrada. 
Tabela 9 - Composição Setorial das Empresas Estudadas - Exercício Global

\begin{tabular}{|c|c|c|c|c|c|c|c|c|c|}
\hline \multirow[t]{2}{*}{ SetorEconomatica } & \multicolumn{3}{|c|}{ Eleição de 2002} & \multicolumn{3}{|c|}{ Eleição de 2006} & \multicolumn{3}{|c|}{ Eleição de 2010} \\
\hline & Controle & Tratamento & Total & Controle & Tratamento & Total & Controle & Tratamento & Total \\
\hline Agro e Pesca & 1 & 1 & 2 & 0 & 1 & 1 & 1 & 2 & 3 \\
\hline Alimentos e Beb & 6 & 3 & 9 & 3 & 2 & 5 & 2 & 7 & 9 \\
\hline Comércio & 2 & 2 & 4 & 2 & 2 & 4 & 5 & 4 & 9 \\
\hline Construção & 1 & 0 & 1 & 3 & 0 & 3 & 6 & 7 & 13 \\
\hline Eletroeletrônicos & 1 & 3 & 4 & 0 & 2 & 2 & 1 & 4 & 5 \\
\hline Energia Elétrica & 8 & 0 & 8 & 7 & 0 & 7 & 6 & 1 & 7 \\
\hline Finanças e Seguros & 0 & 0 & 0 & 0 & 0 & 0 & 0 & 1 & 1 \\
\hline Minerais não Met & 0 & 0 & 0 & 0 & 0 & 0 & 0 & 1 & 1 \\
\hline Mineração & 3 & 0 & 3 & 0 & 1 & 1 & 2 & 0 & 2 \\
\hline Máquinas Indust & 3 & 1 & 4 & 1 & 2 & 3 & 2 & 1 & 3 \\
\hline Outros & 7 & 7 & 14 & 7 & 5 & 12 & 15 & 8 & 23 \\
\hline Papel e Celulose & 0 & 4 & 4 & 0 & 0 & 0 & 0 & 3 & 3 \\
\hline Petróleo e Gas & 1 & 3 & 4 & 2 & 0 & 2 & 2 & 0 & 2 \\
\hline Química & 1 & 4 & 5 & 1 & 5 & 6 & 1 & 4 & 5 \\
\hline Siderur \& Metalur & 7 & 6 & 13 & 8 & 3 & 11 & 4 & 6 & 10 \\
\hline Telecomunicações & 8 & 1 & 9 & 5 & 0 & 5 & 2 & 2 & 4 \\
\hline Textil & 2 & 2 & 4 & 1 & 5 & 6 & 5 & 6 & 11 \\
\hline Transporte Serviç & 0 & 0 & 0 & 2 & 0 & 2 & 6 & 0 & 6 \\
\hline Veiculos e peças & 9 & 3 & 12 & 3 & 3 & 6 & 5 & 5 & 10 \\
\hline Total & 62 & 40 & 102 & 50 & 33 & 83 & 92 & 62 & 154 \\
\hline
\end{tabular}

Fonte: elaboração própria com base nos dados da Economática

Tabela 10 - Composição Setorial das Empresas Estudadas - Exercício Governador

\begin{tabular}{lccccccccc}
\hline SetorEconomatica & \multicolumn{3}{c}{ Eleição 2002} & \multicolumn{3}{c}{ Eleição 2006} & \multicolumn{3}{c}{ Eleição 2010} \\
\hline & Controle & Tratamento & Total & Controle & Tratamento & Total & Controle & Tratamento & Total \\
Agro e Pesca & 2 & 0 & 2 & 1 & 0 & 1 & 3 & 0 & 3 \\
Alimentos e Bebidas & 6 & 3 & 9 & 2 & 1 & 3 & 3 & 6 & 9 \\
Comércio & 3 & 0 & 3 & 2 & 3 & 5 & 5 & 2 & 7 \\
Construção & 4 & 1 & 5 & 3 & 0 & 3 & 12 & 3 & 15 \\
Eletroeletrônicos & 2 & 2 & 4 & 0 & 2 & 2 & 2 & 1 & 3 \\
Energia Elétrica & 6 & 0 & 6 & 7 & 0 & 7 & 9 & 0 & 9 \\
Finanças e Seguros & 0 & 0 & 0 & 0 & 0 & 0 & 0 & 1 & 1 \\
Minerais & 1 & 0 & 1 & 0 & 0 & 0 & 1 & 1 & 2 \\
Mineração & 3 & 0 & 3 & 0 & 1 & 1 & 2 & 0 & 2 \\
Máquinas Industriais & 4 & 1 & 5 & 2 & 1 & 3 & 2 & 1 & 3 \\
Outros & 10 & 1 & 11 & 10 & 1 & 11 & 10 & 6 & 16 \\
Papel e Celulose & 1 & 4 & 5 & 1 & 2 & 3 & 1 & 2 & 3 \\
Petróleo e Gas & 4 & 1 & 5 & 2 & 0 & 2 & 2 & 0 & 2 \\
Química & 4 & 2 & 6 & 2 & 4 & 6 & 2 & 3 & 5 \\
Siderur \& Metalur & 9 & 5 & 14 & 7 & 3 & 10 & 5 & 2 & 7 \\
Software e Dados & 0 & 0 & 0 & 0 & 0 & 0 & 1 & 0 & 1 \\
Telecomunicações & 9 & 0 & 9 & 6 & 0 & 6 & 4 & 0 & 4 \\
Textil & 3 & 3 & 6 & 3 & 2 & 5 & 6 & 6 & 12 \\
Transporte & 0 & 0 & 0 & 1 & 0 & 1 & 6 & 0 & 6 \\
Veiculos e peças & 7 & 3 & 10 & 5 & 3 & 8 & 6 & 4 & 10 \\
\multicolumn{1}{c}{ Total } & $\mathbf{8 1}$ & $\mathbf{2 5}$ & $\mathbf{1 0 6}$ & $\mathbf{6 0}$ & $\mathbf{2 2}$ & $\mathbf{8 2}$ & $\mathbf{1 1 5}$ & $\mathbf{3 8}$ & $\mathbf{1 5 3}$ \\
\hline
\end{tabular}

Fonte: elaboração própria com base nos dados da Economática 


\section{Resultados}

Esta seção apresenta os resultados referentes aos dois exercícios desenvolvidos, quais sejam, Exercício Global e Exercício Governador. Os valores apresentados entre parênteses nas tabelas se referem ao erro-padrão dos coeficientes, ao passo que asteriscos definem significância estatística aos níveis de ${ }^{*}=10 \%,{ }^{* *}=5 \%$ e ${ }^{* *}=1 \%$. Ressalta-se também que o erro-padrão dos coeficientes foi calculado via clustering por empresa.

\subsection{Exercício Global}

A Tabela 11 apresenta os resultados para o Exercício Global. Além da estimação por efeitos fixos, também são apresentados os resultados obtidos por meio dos métodos de efeitos aleatórios e Mínimos Quadrados Ordinários (OLS). A inclusão desses resultados visa complementar a análise do modelo proposto explorando a variação do investimento do governo em ações das diferentes empresas.

O parâmetro de interesse do modelo Diferenças em Diferenças - correspondente à interação entre dummy de grupo de tratamento e dummy de período pós-tratamento apresenta o sinal esperado, em todos os anos estudados, independente do tipo de estimação utilizado. O sinal positivo desse parâmetro aponta o aumento do investimento do governo em ações de empresas tratadas - em relação ao grupo de controle, após o ano eleitoral em função de sua participação no financiamento das campanhas.

Contudo, os resultados para os anos de 2002 e 2006 devem ser interpretados com maior cautela na medida em que não se enquadram nos padrões de significância estatística usuais. A falta de resultados significativos nesses anos pode ter sido influenciada pela escolha de se analisar somente empresas que apresentavam informações para todas as variáveis usadas no modelo. Ainda que esse fato naturalmente represente uma fragilidade do trabalho na medida em que reduz o número de empresas na amostra, acredita-se que os resultados apresentados possam ser relevantes para a análise realizada e, portanto, possam contribuir com a literatura.

Por sua vez, os resultados referentes à eleição de 2010 obtidos via modelo de efeitos fixos sugerem que empresas que doaram recursos para campanhas eleitorais apresentaram aumento de, em média, 1,35\% na participação do governo como sócio acionista em relação ao grupo de controle. Tendo em vista a participação média do governo no quadro acionário das empresas estudadas de 7,03\% - e de 3,75\% para empresas tratadas - durante os oito anos do ciclo eleitoral de 2010, o aumento capturado pelo modelo parece ser de magnitude relevante. O aumento de 1,35\% representa aproximadamente $35 \%$ do valor médio de 
participação do governo no quadro acionário das empresas tratadas, nos oito anos do ciclo eleitoral de 2010; e de 18\% quando consideradas todas as empresas da Bolsa no período.

Adicionalmente, os coeficientes estimados para a Dummy Financiamento apresentam resultados estatisticamente significantes na estimação do tipo efeitos aleatórios para as eleições de 2002 e 2010, e resultados estatisticamente significantes para todos os anos na estimação por OLS. Note que o sinal desta dummy é menor que zero em função da maior participação média do governo como acionista no grupo de controle em comparação com o grupo de tratamento - fator que pode ser verificado nos gráficos das Figuras 6 a 11.

A variável de Ativo Total, também apresenta resultados significativos na estimação pelo método de OLS em todos os anos pesquisados. Esse resultado mostra a importância do tamanho da empresa quanto à decisão de compra de ações no mercado.

Outros regressores estatisticamente significantes encontrados nas eleições de 2010 foram Retorno, Margem Ebitida e Margem Líquida. A primeira variável apresenta efeito significativo sobre a decisão de investimento do governo em ações tanto na estimação obtida pelo método de efeitos fixos quanto pelo método de efeitos aleatórios. As variáveis, Margem Ebitida e Margem Líquida, apesar de apresentarem baixa magnitude, têm alto grau de correlação com a decisão de compra de ações no mercado. Esses resultados demonstram a importância de variáveis relacionadas ao lucro na decisão de investimento de agentes do governo.

\subsection{Exercício Governador}

A Tabela 12 apresenta os resultados do Exercício Governador. Mais uma vez o parâmetro de interesse da equação do tipo Diferenças em Diferenças apresenta sinal positivo em todas as estimações aplicadas aos anos estudados. Contudo, como no exercício anterior, os resultados para os anos de 2002 e 2006 não se enquadram nos padrões de significância estatística usuais. Mais uma vez, o nível de significância desses resultados pode ser função da restrição da análise às empresas com informações para todas as variáveis usadas no modelo.

Já os resultados da análise para as eleições de 2010 apresentam, novamente, efeito estatisticamente significante do financiamento eleitoral. Em particular, para os resultados obtidos por meio da estimação do tipo efeitos fixos, empresas que doaram para campanhas de governadores apresentaram aumento de, em média, 1,81\% na participação do governo como sócio acionista em relação ao grupo de controle nos anos posteriores à eleição.

O resultado apresenta magnitude maior em relação ao Exercício Global, tendo em vista que a participação média do governo no quadro acionário das empresas estudadas no Exercício Governador foi de 7,71\% - e de 4,52\% para empresas tratadas - durante os oito 
anos do ciclo eleitoral de 2010. Neste caso, o aumento de 1,81\% representa $40 \%$ do valor médio de participação do governo no quadro acionário das empresas tratadas, nos oito anos do ciclo eleitoral de 2010; e de 23\% quando consideradas todas as empresas da Bolsa no mesmo período.

O parâmetro de interesse em 2010 também apresente efeito estatisticamente significante do financiamento eleitoral na estimação do tipo efeitos aleatórios. Empresas que doaram para campanhas de governadores apresentaram aumento de, em média, 1,74\% na participação do governo como sócio acionista em relação ao grupo de controle. Esse aumento representa aproximadamente $38 \%$ do valor médio de participação do governo no quadro acionário das empresas tratadas no ciclo eleitoral estudado.

Dado que o efeito positivo observado no ano de 2010 é constatado tanto via estimador de efeitos fixos (que considera somente variações do tipo within) como estimador de efeitos aleatórios (que considera tanto as variações within como as variações between), o resultado reforça a evidência de que nas eleições para governador estadual de 2010 o financiamento eleitoral parece ter exercido efeito, via influência política, na decisão de investimento do governo em ações de companhias da bolsa.

Os resultados com maior nível de significância no Exercício Governador em relação ao exercício anterior podem ser interpretados como uma evidência em favor da hipótese de que governadores exercem maior influência sobre as instituições políticas classificadas como associadas ao governo na construção da variável dependente. ${ }^{9}$. Assim, a análise conjunta dos exercícios realizados para a eleição de 2010 permite supor que os cargos eletivos apresentam diferentes graus de poder de influência.

Os coeficientes estimados para a Dummy Financiamento apresentam, mais uma vez, resultados estatisticamente significantes com sinal negativo. Nesse exercício os resultados para esse regressor são significantes na estimação do tipo efeitos aleatórios para as eleições de 2006 e 2010. O sinal negativo, mais uma vez, ocorre em função da maior participação média do governo como acionista no grupo de controle em comparação com o grupo de tratamento - fator que pode ser verificado nos gráficos das Figuras 6 a 11.

Por fim, mais uma vez a variável Retorno apresentou resultado significativo na análise das eleições de 2010, em todos os métodos de estimação implementados. A variável de Ativo Total apresenta resultados significativos na estimação pelo método de OLS em todos os anos pesquisados, e as variáveis Margem Ebitida e Margem Líquida têm, novamente, alto grau de correlação com a decisão de compra de ações no mercado. Esses resultados demonstram a importância de variáveis relacionadas ao lucro na decisão de investimento de agentes do governo. O resultado reforça a evidência em favor da importância de variáveis de lucro na decisão de investimento de agentes do governo.

$9 \quad$ A Tabela 13 apresenta a lista de acionistas classificados como agentes governamentais dentro do quadro acionário das empresas estudadas. 


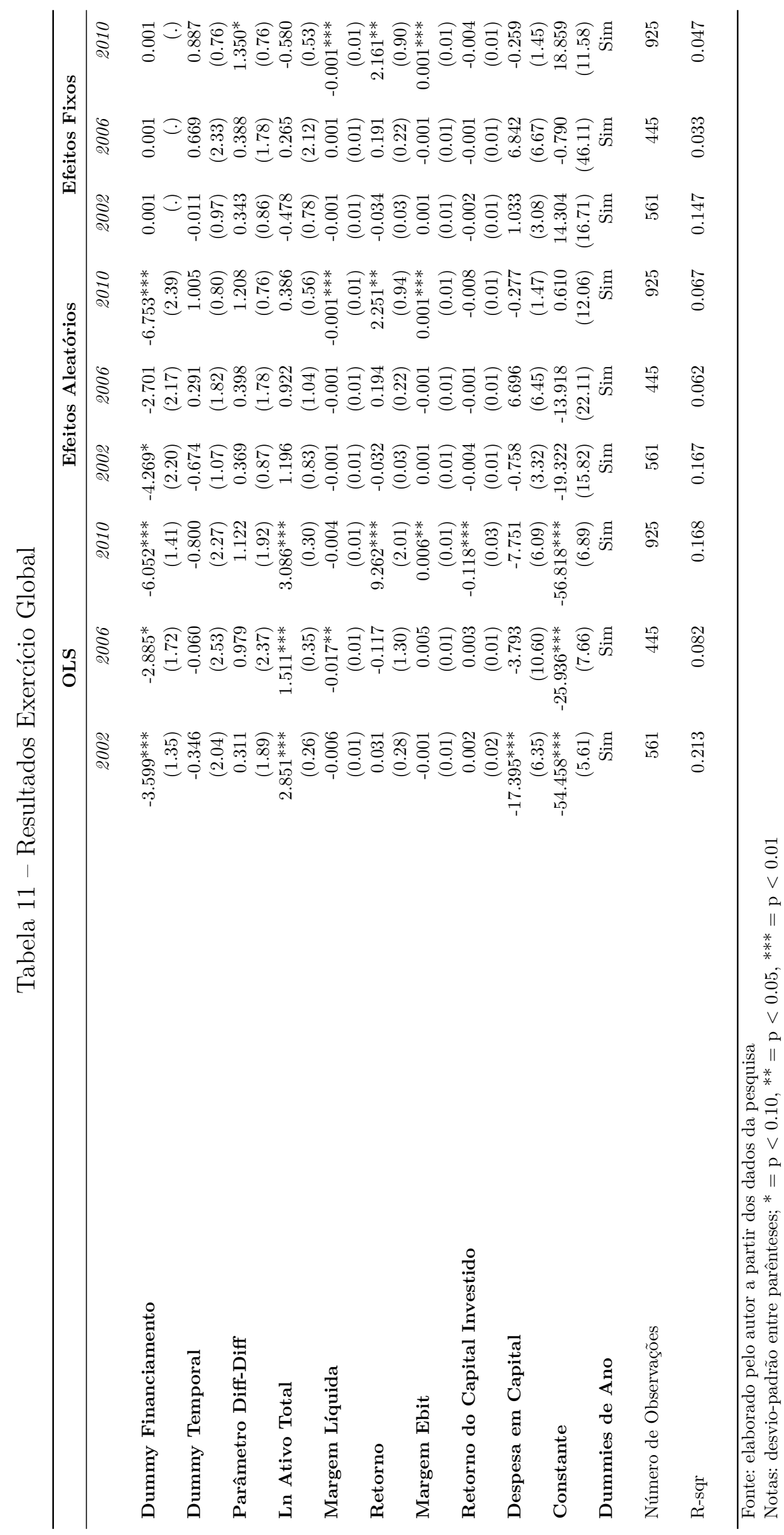




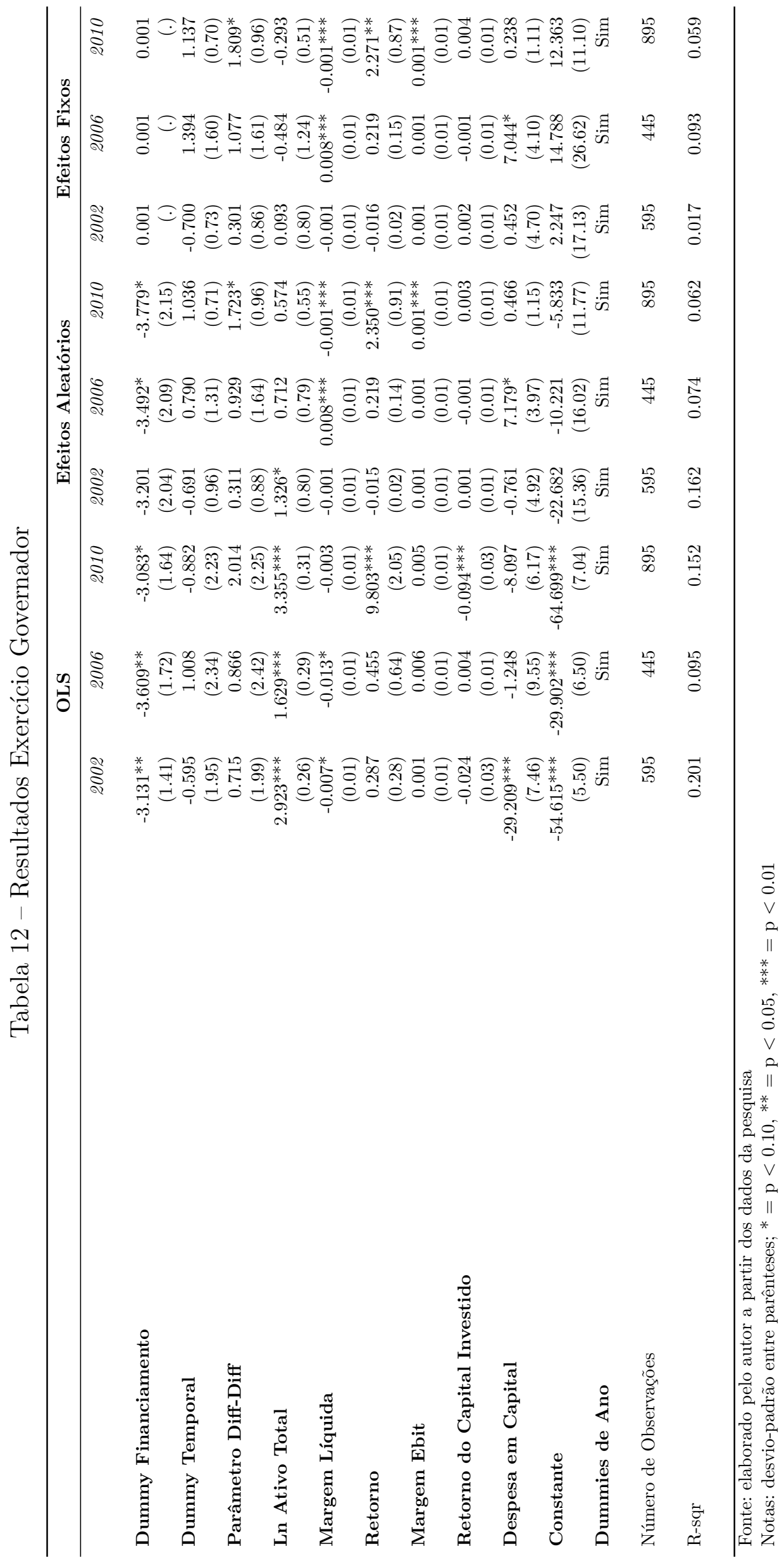




\section{Considerações finais}

O estudo dos incentivos que permeiam os agentes envolvidos no financiamento eleitoral é fundamental para a manutenção de um processo democrático sem vícios. Este trabalho propôs a análise da compra de ações de empresas de capital aberto por parte do governo como mecanismo de compensação do financiamento de campanhas eleitorais a fim de contribuir para a compreensão dos desdobramentos, dentro do contexto eleitoral brasileiro, que o processo de financiamento de campanhas pode causar.

Por meio da análise e tratamento intensivo dos dados eleitorais disponibilizados pelo TSE, foi elaborado um panorama do financiamento eleitoral brasileiro possibilitando maior compreensão desse contexto e contribuindo para questões relacionadas ao tema como: a origem de seus recursos, a discriminação dos agentes financiadores de campanhas eleitorais e, testando um possível mecanismo de barganha com empresas no papel de agentes financiadores, o porquê da existência de organizações dispostas a financiar campanhas eleitorais.

Verificou-se a possibilidade de empresas que financiam campanhas eleitorais receberem posteriormente maior participação de instituições governamentais como sócios acionistas devido à influência política de candidatos financiados. Essa proposta contribui para a literatura por considerar uma variável dependente até então inexplorada. Outra contribuição reside na análise de eleições mais atuais, cuja disponibilidade de dados, somente em um período recente, possibilitou análises quantitativas e qualitativas.

Esta análise comparou a participação acionária do governo em empresas doadoras e não doadoras de campanha, antes e depois das eleições de 2002, 2006 e 2010, em dois exercícios. No primeiro, foram consideradas as doações para todos os cargos. No segundo foram isoladas as doações para campanhas de Governadores Estaduais. Em ambos os casos assume-se que os benefícios advindos da influência política ocorrem durante o mandato para o qual o governo foi eleito.

Por meio do método de Diferenças em Diferenças os resultados para os anos de 2002 e 2006 em ambos os exercícios propostos não apresentam evidência suficiente para corroborar a hipótese de que o investimento do governo em ações é um mecanismo pelo qual se desenvolve a barganha entre candidatos eleitorais e agente financiadores.

Há dois fatores que podem explicar a falta de resultados estatisticamente robustos para as análises desenvolvidas nesses anos. Em primeiro lugar, a falta de informações financeiras no banco de dados diminui o número de empresas que efetivamente compõem a amostra em estudo. Além de prejudicar os resultados, esse fator diminui a validade externa dos mesmos. 
Em segundo lugar, a construção da variável dependente do trabalho - feita a partir da classificação dos acionistas das empresas abertas - pode ter omitido agentes sobre os quais a influência política pode se desenvolver. A omissão de algum agente governamental relevante pode alterar a composição do grupo de tratamento e controle dentro da análise e assim prejudicar os resultados.

Apesar da falta de resultados robustos para os dois primeiros anos, os exercícios aplicados às eleições de 2010 apresentaram evidência em favor da hipótese de aumento do investimento do governo em ações causado pela participação de empresas no financiamento de campanhas eleitorais. Os resultados apresentados tendem à suposição de que, no ciclo eleitoral de 2010, o investimento do governo em ações funcionou como mecanismo de compensação do financiamento eleitoral no âmbito de empresas abertas no Brasil.

Em suma, ainda que os resultados obtidos nos exercícios do ciclo eleitoral de 2010 apontem o investimento governamental como método de compensação, a evidência empírica de um único ciclo eleitoral não permite corroborar a hipótese de que a prática seja um mecanismo de barganha recorrente no Brasil.

Cabe ainda ressaltar que os resultados com maior nível de significância no Exercício Governador em relação ao Exercício Global podem ser interpretados como uma evidência em favor da hipótese de que esse cargo exerce maior influência sobre as instituições políticas interpretadas como agentes do governo neste trabalho. Sendo assim, a análise concomitante dos exercícios implementados na eleição de 2010 permite a suposição de que os cargos eletivos apresentam diferentes graus de poder de influência.

É importante salientar que os resultados desta pesquisa não indicam a inexistência de barganha entre candidatos eleitorais e financiadores dentro do processo de financiamento de campanhas eleitorais. Os resultados tão somente apresentam evidência de que o investimento em ações não parece ser um mecanismo pelo o qual essa compensação acontece recorrentemente.

A verificação do investimento governamental em ações como mecanismo de compensação pelo financiamento de campanhas eleitorais poderá gerar resultados ainda mais robustos no futuro, na medida em que os dados relacionados à prestação de contas e à atuação de instituições eleitorais continuem a evoluir no Brasil. Análises para eleições de 2014, por exemplo, serão possíveis assim que houver dados suficientes para a avaliação dos efeitos do financiamento eleitoral sobe variáveis financeiras das empresas.

Ainda que o investimento do governo em ações não seja um mecanismo pelo qual os agentes envolvidos nos processos de financiamento eleitoral barganham, o estudo desses incentivos deve ser realizado constantemente tendo em vista sua importância nos processos democráticos da sociedade. A compreensão desses incentivos é vital na manutenção da credibilidade da democracia perante a sociedade e o tempo. 


\section{Referências}

ARVATE, P.; BARBOSA, K. d. S.; FUZITANI, E. Campaign donation and government contracts in brazilian states. 2013. Citado 2 vezes nas páginas 16 e 20.

ASHENFELTER, O.; CARD, D. Using the longitudinal structure of earnings to estimate the effect of training programs. [S.l.], 1984. Citado na página 33.

BAEK, M. A comparative analysis of political communication systems and voter turnout. American Journal of Political Science, Wiley Online Library, v. 53, n. 2, p. 376-393, 2009. Citado na página 18.

BALlingtON, J.; AUSTIN, R.; TJERNSTROM, M. Funding of Political Parties and Election Campaign - A Handbook on Political Finance. [S.l.]: International Institute for Democracy and Electoral Assistence, 2014. Citado 2 vezes nas páginas 12 e 15.

BENTAL, B.; BEN-ZION, U. Political contribution and policy. Public Choice, Springer, v. 24, n. 1, p. 1-12, 1975. Citado na página 18.

BESLEY, T.; CASE, A. Does electoral accountability affect economic policy choices? Evidence from gubernatorial term limits. [S.l.], 1993. Citado na página 18.

BOAS, T. C.; HIDALGO, F. D.; RICHARDSON, N. P. The spoils of victory: campaign donations and government contracts in brazil. the Journal of Politics, Cambridge Univ Press, v. 76, n. 02, p. 415-429, 2014. Citado 3 vezes nas páginas 16, 20 e 29.

CAMPANTE, F. R. Redistribution in a model of voting and campaign contributions. Journal of Public Economics, Elsevier, v. 95, n. 7, p. 646-656, 2011. Citado na página 19.

CARD, D.; KRUEGER, A. B. Minimum wages and employment: A case study of the fast-food industry in new jersey and pennsylvania. The American Economic Review, v. 84, n. 4, September 1994. Citado 2 vezes nas páginas 33 e 35.

CLAESSENS, S.; FEIJEN, E.; LAEVEN, L. Political connections and preferential access to finance: The role of campaign contributions. Journal of Financial Economics, Elsevier, v. 88, n. 3, p. 554-580, 2008. Citado 6 vezes nas páginas 16, 19, 20, 27,28 e 29.

COATE, S. Pareto-improving campaign finance policy. American Economic Review, JSTOR, p. 628-655, 2004. Citado na página 19.

ELEITORAL, T. S. Financiamento de Campanha Eleitoral: Bibliografia Selecionada. [S.l.], 2012. Citado na página 14.

GEORGE, H. Money in elections. The North American Review, v. 136, n. 316, March 1883. Citado na página 17.

GOMES, J. J. Direito Eleitoral. [S.l.]: Atlas, 2012. Citado na página 14.

HOGAN, R. E. State campaign finance laws and interest group electioneering activities. Journal of Politics, Wiley Online Library, v. 67, n. 3, p. 887-906, 2005. Citado na página 18. 
KINZO, M. D. Os partidos no eleitorado: percepções públicas e laços partidários no Brasil. [S.l.]: SciELO Brasil, 2006. Citado na página 19.

LAZZARINI, S. G. et al. What do state-owned development banks do? evidence from bndes, 2002-09. World Development, 2015. Citado na página 27.

MORTON, R.; CAMERON, C. Election and the theory of campaign contributions: a survey and critical analysis. Economics and Politics, v. 4, n. 1, March 1992. Citado 3 vezes nas páginas 14, 17 e 29.

PALDA, K. S. Does advertising influence votes? an analysis of the 1966 and 1970 quebec elections. Canadian Journal of Political Science, Cambridge Univ Press, v. 6, n. 04, p. 638-655, 1973. Citado na página 17.

PIERRE, M. Dicionario Juridico. [S.l.: s.n.], 2008. Citado na página 14.

SCHLICKMANN, D. G.; LUBKE, H. H. B. S. Financiamento de campanhas eleitorais: avaliacao das proposicoes apresentadas pelo tribunal superior eleitoral ao congresso nacional. Resenha Eleitoral, v. 15, 2008. Citado na página 16.

UNIT, T. E. I. Democracy Index 2015: Democracy in an age of anxiety. [S.1.], 2015. Citado na página 14. 
Apêndices 


\section{APÊNDICE A - Protocolo de Construção do Painel para Governadores}

O painel usado no Exercício Governador apresenta informações sobre a participação de empresas abertas no financiamento de campanhas eleitorais para o cargo de governador estadual. Para a construção desse painel, os dados do TSE foram tratados com filtros e manipulações não prontamente disponíveis na fonte original. Esta seção explica o tratamento desses dados.

O Exercício Governador demanda o mapeamento das doações, tanto diretas quanto indiretas, de sociedades anônimas para campanhas de candidatos a governos estaduais. Para a extração dessas informações usam-se as três bases de receita presentes na base Prestação de Contas.

A base Receita Candidato discrimina as Doações Diretas e os repasses feitos aos candidatos para financiar suas campanhas. Usando essa base não é possível mapear as Doações Indiretas de sociedades anônimas. Isso ocorre porque em Receita Candidato não se discrimina a origem de recursos provenientes de repasses de comitês eleitorais e partidos políticos. Logo, a partir dessa base, não é possível atribuir repasses a empresas.

Para mapear as Doações Indiretas é preciso utilizar as bases de Receita Comitê e Receita Partido. Por meio dessas bases é possível determinar o montante doado por empresas de capital aberto para comitês e partidos. Todavia, não é razoável assumir que essas doações sejam repassadas em sua totalidade especificamente para candidatos a governador.

Comitês eleitorais e partidos políticos têm candidatos para diversos cargos eletivos, de modo que seus repasses para cada cargo devem diferir dos valores doados por empresas. Dessa maneira, é preciso estimar a parte do montante doado a comitês e partidos por sociedades anônimas que cabe aos candidatos a governador estadual. Essa estimação consiste numa ponderação das Doações Indiretas.

A ponderação usa a proporção de repasses feitos para cada cargo, por cada comitê e cada partido, dentro de uma unidade da federação. Essa informação está presente em Receita Candidato. Se por exemplo a empresa Petrobrás S.A. doou no ano de 2002 o valor de $R \$ 200.000$ para o Diretório Estadual do PSDB na Bahia, não é razoável assumir que essa doação tenha sido repassada integralmente ao candidato do PSDB ao governo da Bahia e sim distribuída entre todos os candidatos do partido nesse estado.

A partir da base Receita Candidato verifica-se que o Diretório Estadual do PSDB na 
Bahia fez repasses de $50 \%$ dos recursos para candidatos a governador, $30 \%$ para candidatos a presidente, e $20 \%$ para candidatos a deputado federal no ano de 2002. A ponderação irá estimar que a doação da Petrobrás S.A. para o candidato a governador do PSDB na Bahia foi de $R \$ 200.000 * 50 \%=R \$ 100.000$.

Ao ponderar as doações de empresas abertas para comitês e partidos, pode-se tratálas efetivamente como doações diretas para candidatos, eliminando o intermédio dos comitês e partidos no processo de financiamento. Por meio desse procedimento, são mapeadas todas as doações de sociedades anônimas para candidatos a governador empilhando verticalmente Doações Diretas e Doações Indiretas ponderadas. 


\section{APÊNDICE B - Lista de Acionistas Classificados como Agentes do Governo}

Tabela 13 - Lista de Acionistas Classificados como Agentes do Governo

\footnotetext{
AES Cemig Empreendimentos

Banco Banerj S/A

Banco Banestado S/A

Banco do Brasil

Banco do Estado de Sao Paulo S/A - Banespa .

Banco Nac. de Des. Economico Social

Banco Nacional de Investimentos

Banco Nacional S/A

Banco Regional de Desenv Ext Sul

Banespa S/A Adm Cart e Servicos

Banespa S/A Corret Cambio e Titulo

Banesprev Fundo Banespa Seg Soc

Banesprev Mais Valor Acoes - Fundo de Investimentos

Banestado Participacoes, Adm e Servs.Ltd

Banestado S/A Corr. de Seguros

BB Acoes Price II FIA

BB Banco de Investimento S/A

BB Carteira Livre I Fundo de Investimento em Acoes

BB Dtvm S/A

BB Fgeduc - Fundo de Investimento Multimercado

BB Fgo - Fundo de Investimento em Acoes

BB FIF Leverage

BB Top Acoes Dividendos FIA

BNDES - Banco Nac de Desenvol Economico e Social

Bndespar - BNDES Participacoes SA

Bolsa de Minas/Espirito Santo/B

Caixa Adm. Div. Pub. Estado-Cadip

Caixa Benef Func do Banespa/Cabesp

Caixa Dos Empregados da Usiminas

Caixa Economica Federal

Caixa Prev Func Banerj Previ
} 
Caixa Prev Func BNB - Capef

Caixa Previd Dos Funcionarios do Banco do Brasil S.A.

Caixa Seguros Holding S.A.

CBC - Cia. Brasileira de Cartuchos

Cemig - Cia Energetica de MG

Cemig Geracao e Transmissao S.A

Centrais Eletricas de Santa Catarina

Cesp Cia Energetica de Sao Paulo

Cia de Desenv. do Est. de Sta. Catarina - Codesc

Clube de Investimentos Usiminas - Ciu

Departamento de Aguas e Energia Eletrica - Daee

Eletrobras - Centrais Eletricas Brasileiras S.A.

Estado de Goias

Estado de Minas Gerais

Estado de Pernambuco

Estado de Santa Catarina

Estado do Ceara

Estado do Maranhao

Estado do Para

Estado do Parana

Estado do Piaui

Estado do Rio de Janeiro

Estado do Rio Grande do Sul

Federacao Nacional Das Associacoes de Pessoal da Caixa Economica Federal - Fenae

Ffie - Fundo Fiscal de Investimentos e Estabilizacao

FIA - BB Carteira Ativa

Financiadora de Estudos e Projetos Finep

Fmia - Carteira Livre I

Fmia Carteira Livre BB

Fnd Fundo Nacional de Desenvolvimento

Funcef-Fundacao Economiarios Federais

Fund A e Prev Social do BNDES/Fapes

Fund Seg Soc Embrapa Embrater/Ceres

Fundacao Baneb de Seg. Social Base

Fundacao Banestado de Seg. Social

Fundacao Banestes de Seg. Social

Fundacao Banrisul de Seg Social

Fundacao Bco.Central Prev.Priv. -Centrus

Fundacao Cesp 
Fundacao Eletrobras de Seguridade Social Eletros

Fundo de Educacao Para O Brasil FIP

Fundo de Gar de Op de Cred Educ Fgeduc

Fundo de Invest. do Nordeste-Finor

Fundo de Invest. em Participacoes da Serra (FIP da Serra)

Fundo de Investimento do Fundo de Garantia do Tempo de Servico - FI-FGTS

Fundo de Investimento em Participacoes Caixa Ambiental - FIP Caixa Ambiental

Fundo Garantidor A Exportacao

Fundo Garantidor Das Parcerias Publico - Privadas do Parana

Fundo Garantidor de Habitacao Fghab

Fundo Invest Amazonia - Finam

Fundo Mutuo Inv. em Acoes Cart.Liv - BB Acoes Price

Fundo Mutuo Inv. Financ BB Renda Fixa IV

Fundo Seg Social Bco Economico

Gov. Federal - Minist. Minas e Energia

Governo do Distrito Federal

Governo do Estado de Sao Paulo

Governo do Estado de Sergipe

Governo do Estado do Espirito Santo

Municipios

Nossa Caixa Nosso Banco S/A

Outras Empresas do Estado de M. Ger

Petrobras Quimica S/A Petroquisa

Petroleo Brasileiro S/A Petrobras

Petros - Fund. Petrobras de Seg. Social

Pmsp Prefeitura Mun Sao Paulo

Postalis Inst. Seguridade Social Dos Correios e Telegraf.

Prefeitura Municipal de Belem

Prefeitura Municipal de Belo Horizonte

Prefeitura Municipal de Ribeirao Preto

Prefeituras Municipais

Sec de Est da Faz de Santa Catarina

Sec de Est de Faz do Distrito Federal

Superintendencia de Desenv da Amazonia

Tesouro Nacional/Fnde

Uniao Federal (Tesouro Nacional) 


\section{APÊNDICE C - Lista de Empresas}

Tabela 14 - Lista de Empresas Exercício Global 2002

Exercício Global 2002

\begin{tabular}{|c|c|}
\hline Empresa Não Doadoras & Empresas Doadoras \\
\hline Albarus ON (ALBA3) & Aliperti PN (APTI4) \\
\hline Alfa Consorc PNE (BRGE11) & Am Inox BR ON (ACES3) \\
\hline Alfa Holding ON (RPAD3) & Aracruz ON (ARCZ3) \\
\hline Alpargatas PN (ALPA4) & Arcelor BR ON (ARCE3) \\
\hline Ambev S/A PN (AMBV4) & Bardella PN (BDLL4) \\
\hline Ampla Energ ON (CBEE3) & Cedro ON (CEDO3) \\
\hline BRF SA ON (BRFS3) & Copesul ON (CPSL3) \\
\hline Bic Monark ON (BMKS3) & Dimed PN (PNVL4) \\
\hline Cacique PN (CIQU4) & Dixie Toga PN (DXTG4) \\
\hline Caemi PN (CMET4) & Docas PN (DOCA4) \\
\hline Ceb PNB (CEBR6) & Duratex.Old ON (DURA3) \\
\hline Celpe PNB (CEPE6) & Ferbasa PN (FESA4) \\
\hline Cemig ON (CMIG3) & Gerdau PN (GGBR4) \\
\hline D F Vasconc ON (DFVA3) & Grazziotin PN (CGRA4) \\
\hline DHB ON (DHBI3) & Guararapes PN (GUAR4) \\
\hline Elektro PN (EKTR4) & Hoteis Othon PN (HOOT4) \\
\hline Eletrobras PNB (ELET6) & Iguacu Cafe ON (IGUA3) \\
\hline Eletropaulo PNA (ELPL5) & Ipiranga Dis ON (DPPI3) \\
\hline Eleva ON (ELEV3) & Ipiranga Pet PN (PTIP4) \\
\hline Eluma PN (ELUM4) & Ipiranga Ref PN (RIPI4) \\
\hline Embraco PN (EBCO4) & Itautec ON (ITEC3) \\
\hline Embratel Part ON (EBTP3) & Klabin S/A ON (KLBN3) \\
\hline Energisa Mt PN (ENMT4) & Leco PN (LECO4) \\
\hline Estrela ON (ESTR3) & Marcopolo ON (POMO3) \\
\hline Excelsior PN (BAUH4) & Oi PN (OIBR4) \\
\hline F Cataguazes PNB (FLCL6) & Petroflex PNA (PEFX5) \\
\hline Fras.Le PN (FRAS4) & Pronor PNA (PNOR5) \\
\hline Gerdau Met ON (GOAU3) & Randon Part ON (RAPT3) \\
\hline Granoleo PN (GRNL4) & Rasip Agro ON (RSIP3) \\
\hline Inds Romi PN (ROMI4) & Ripasa PN (RPSA4) \\
\hline Iochp.Maxion ON (MYPK3) & Sansuy PNA (SNSY5) \\
\hline
\end{tabular}


Lix da Cunha ON (LIXC3)

Lojas Americ ON (LAME3)

Lojas Hering ON (LHER3)

Magnesita ON (MAGS3)

Manasa ON (MNSA3)

Mangels Indl PN (MGEL4)

Panatlantica PN (PATI4)

Paranapanema ON (PMAM3)

Petrobras ON (PETR3)

Plascar Part PN (PLAS4)

Pro Metalurg PNB (PMET6)

Recrusul PN (RCSL4)

Rede Energia ON (REDE3)

SPturis PNA (AHEB5)

Sabesp ON (SBSP3)

Souza Cruz ON (CRUZ3)

Teka PN (TEKA4)

Tekno PN (TKNO4)

Tele Sudeste Celula PN (TSEP4)

Telef Brasil PN (VIVT4)

Telemar PN (TNLP4)

Telemig Part ON (TMCP3)

Tim Part S/A PN (TCSL4)

Tim Sul PNB (TPRC6)

Trafo PN (TRFO4)

Tupy PN (TUPY4)

Ultrapar PN (UGPA4)

Usiminas PNA (USIM5)

Vale PNA (VALE5)

Vivo ON (VIVO3)

Weg PN (WEGE4)
Saraiva Livr PN (SLED4)

Sid Nacional ON (CSNA3)

Springer PNB (SPRI6)

Suzano Papel PNA (SUZB5)

Tectoy PN (TOYB4)

Unipar ON (UNIP3)

Vigor PN (VGOR4)

Wetzel S/A ON (MWET3)

Whirlpool ON (WHRL3) 
Tabela 15 - Lista de Empresas Exercício Global 2006

Exercício Global 2006

\begin{tabular}{|c|c|}
\hline Empresa Não Doadoras & Empresas Doadoras \\
\hline AES Elpa ON (AELP3) & Alpargatas PN (ALPA4) \\
\hline Acos Vill ON (AVIL3) & Aracruz PNB (ARCZ6) \\
\hline Alfa Consorc ON (BRGE3) & Bardella PN (BDLL4) \\
\hline Alfa Holding PNA (RPAD5) & Braskem PNA (BRKM5) \\
\hline All Amer Lat PN (ALLL4) & Cia Hering ON (HGTX3) \\
\hline Ambev S/A PN (AMBV4) & Confab PN (CNFB4) \\
\hline Ampla Energ ON (CBEE3) & Dimed ON (PNVL3) \\
\hline Bic Monark ON (BMKS3) & Docas PN (DOCA4) \\
\hline CCR SA ON (CCRO3) & Dohler PN (DOHL4) \\
\hline Cacique ON (CIQU3) & Elekeiroz ON (ELEK3) \\
\hline Ceb ON (CEBR3) & Fab C Renaux PN (FTRX4) \\
\hline Celpa PNC (CELP7) & Forja Taurus PN (FJTA4) \\
\hline Cemig ON (CMIG3) & Grazziotin ON (CGRA3) \\
\hline Cesp PNA (CESP5) & Guararapes PN (GUAR4) \\
\hline Coelce PNB (COCE6) & Inds Romi ON (ROMI3) \\
\hline Comgas PNA (CGAS5) & Itautec ON (ITEC3) \\
\hline Const A Lind PN (CALI4) & Klabin S/A PN (KLBN4) \\
\hline Elektro PN (EKTR4) & Marcopolo ON (POMO3) \\
\hline Eletrobras PNA (ELET5) & Mont Aranha ON (MOAR3) \\
\hline Eluma PN (ELUM4) & Net PN (NETC4) \\
\hline Embratel Part PN (EBTP4) & Pronor PNA (PNOR5) \\
\hline Energisa Mt PN (ENMT4) & Quattor Petr PN (SZPQ4) \\
\hline Excelsior PN (BAUH4) & Randon Part ON (RAPT3) \\
\hline Gerdau Met ON (GOAU3) & Rasip Agro PN (RSIP4) \\
\hline Itausa PN (ITSA4) & Sadia S/A ON (SDIA3) \\
\hline Lix da Cunha ON (LIXC3) & Sid Nacional ON (CSNA3) \\
\hline Lojas Americ ON (LAME3) & Sondotecnica PNB (SOND6) \\
\hline Mangels Indl PN (MGEL4) & Tectoy ON (TOYB3) \\
\hline Marisol PN (MRSL4) & Unipar ON (UNIP3) \\
\hline Melhor SP PN (MSPA4) & Vale PNA (VALE5) \\
\hline Metal Leve PN (LEVE4) & Vigor PN (VGOR4) \\
\hline Panatlantica ON (PATI3) & Wetzel S/A ON (MWET3) \\
\hline Par Al Bahia ON (PEAB3) & Whirlpool ON (WHRL3) \\
\hline \multicolumn{2}{|l|}{ Paranapanema ON (PMAM3) } \\
\hline Petrobras ON (PETR3) & \\
\hline
\end{tabular}


Rede Energia ON (REDE3)

Rossi Resid ON (RSID3)

Sabesp ON (SBSP3)

Sanepar PN (SAPR4)

Souza Cruz ON (CRUZ3)

Tekno PN (TKNO4)

Telef Brasil ON (VIVT3)

Telemig Part PN (TMCP4)

Tim Part S/A ON (TIMP3)

Tupy ON (TUPY3)

Ultrapar PN (UGPA4)

Usiminas PNB (USIM6)

Vivo PN (VIVO4)

Weg ON (WEGE3)

Wlm Ind Com PN (SGAS4) 
Tabela 16 - Lista de Empresas Exercício Global 2010

Exercício Global 2010

\begin{tabular}{|c|c|}
\hline Empresas Não Doadoras & Empresas Doadoras \\
\hline AES Elpa ON (AELP3) & Alpargatas ON (ALPA3) \\
\hline AES Tiete ON (GETI3) & BRF SA ON (BRFS3) \\
\hline Afluente ON (AFLU3) & Bematech ON (BEMA3) \\
\hline Alfa Consorc ON (BRGE3) & BmfBovespa ON (BVMF3) \\
\hline Alfa Holding ON (RPAD3) & Braskem ON (BRKM3) \\
\hline All Amer Lat ON (ALLL3) & Cedro ON (CEDO3) \\
\hline Ambev S/A ON (ABEV3) & Celul Irani ON (RANI3) \\
\hline Ampla Energ ON (CBEE3) & Cia Hering ON (HGTX3) \\
\hline Ampla Invest ON (AMPI3) & Contax ON (CTAX3) \\
\hline Arteris ON (ARTR3) & Cosan ON (CSAN3) \\
\hline BHG ON (BHGR3) & Csu Cardsyst ON (CARD3) \\
\hline BR Brokers ON (BBRK3) & Cyrela Realt ON (CYRE3) \\
\hline BR Malls Par ON (BRML3) & Dasa ON (DASA3) \\
\hline Bic Monark ON (BMKS3) & Dimed ON (PNVL3) \\
\hline Brasilagro ON (AGRO3) & Duratex ON (DTEX3) \\
\hline Brookfield ON (BISA3) & Elekeiroz ON (ELEK3) \\
\hline CCR SA ON (CCRO3) & Embraer ON (EMBR3) \\
\hline CPFL Energia ON (CPFE3) & Eternit ON (ETER3) \\
\hline Cacique ON (CIQU3) & Even ON (EVEN3) \\
\hline Casan ON (CASN3) & Fer Heringer ON (FHER3) \\
\hline Ceb ON (CEBR3) & Ferbasa ON (FESA3) \\
\hline Celesc ON (CLSC3) & Forja Taurus ON (FJTA3) \\
\hline Cemar ON (ENMA3B) & Gafisa ON (GFSA3) \\
\hline Cemig ON (CMIG3) & Gerdau ON (GGBR3) \\
\hline Cesp ON (CESP3) & Grazziotin ON (CGRA3) \\
\hline Coelba ON (CEEB3) & Grendene ON (GRND3) \\
\hline Coelce ON (COCE3) & Guararapes ON (GUAR3) \\
\hline Comgas ON (CGAS3) & Hypermarcas ON (HYPE3) \\
\hline Copasa ON (CSMG3) & Inds Romi ON (ROMI3) \\
\hline Copel ON (CPLE3) & Iochp.Maxion ON (MYPK3) \\
\hline Cosern ON (CSRN3) & Itautec ON (ITEC3) \\
\hline Coteminas ON (CTNM3) & JBS ON (JBSS3) \\
\hline Cremer ON (CREM3) & Josapar ON (JOPA3) \\
\hline Cyre Com.Ccp ON (CCPR3) & Klabin S/A ON (KLBN3) \\
\hline Elektro ON (EKTR3) & Localiza ON (RENT3) \\
\hline
\end{tabular}




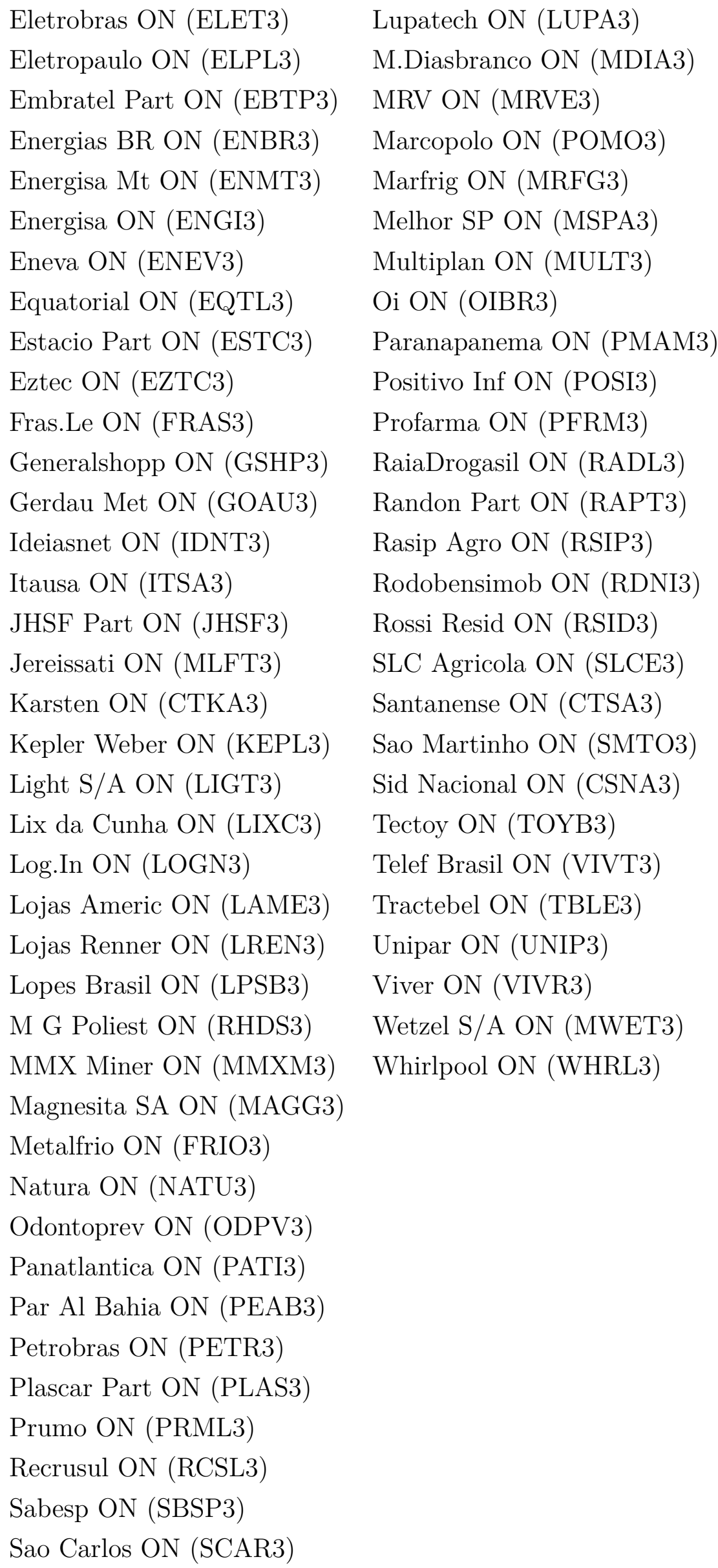


Saraiva Livr ON (SLED3)

Souza Cruz ON (CRUZ3)

Springer ON (SPRI3)

Springs ON (SGPS3)

Tecnisa ON (TCSA3)

Tegma ON (TGMA3)

Tempo Part ON (TEMP3)

Tim Part S/A ON (TIMP3)

Tran Paulist ON (TRPL3)

Trisul ON (TRIS3)

Triunfo Part ON (TPIS3)

Tupy ON (TUPY3)

Usiminas ON (USIM3)

V.Agro ON (VAGR3)

Viavarejo ON (VVAR3)

Vulcabras ON (VULC3)

Weg ON (WEGE3)

Wlm Ind Com ON (SGAS3) 
Tabela 17 - Lista de Empresas Exercício Governador 2002

Exercício Governador 2002

\section{Empresas Não Doadoras}

Acos Vill ON (AVIL3)

Albarus ON (ALBA3)

Alfa Consorc PND (BRGE8)

Alfa Holding PNB (RPAD6)

Alpargatas PN (ALPA4)

Ambev S/A ON (ABEV3)

Ampla Energ ON (CBEE3)

Arcelor BR PN (ARCE4)

BRF SA PN (PRGA4)

Bandeirante Energ PN (EBEN4)

Bardella PN (BDLL4)

Bic Monark ON (BMKS3)

Cacique ON (CIQU3)

Caemi PN (CMET4)

Ceb ON (CEBR3)

Cemig ON (CMIG3)

Const Beter PNB (COBE6B)

Cyrela Realt PN (CYRE4)

D F Vasconc ON (DFVA3)

DHB ON (DHBI3)

Dimed PN (PNVL4)

Docas PN (DOCA4)

Duratex.Old PN (DURA4)

Elektro PN (EKTR4)

Eletrobras PNB (ELET6)

Eleva ON (ELEV3)

Embraco ON (EBCO3)

Embratel Part ON (EBTP3)

Energisa Mt ON (ENMT3)

Estrela PN (ESTR4)

Eternit ON (ETER3)

F Cataguazes PNA (FLCL5)

Fibria PN (VCPA4)

Gerdau Met PN (GOAU4)

\section{Empresas Doadoras}

Am Inox BR PN (ACES4)

Aracruz ON (ARCZ3)

Buettner PN (BUET4)

CBC Cartucho PN (CCTU4)

Cedro PN (CEDO4)

Confab PN (CNFB4)

Copesul ON (CPSL3)

Eucatex PN (EUCA4)

Gerdau ON (GGBR3)

Guararapes PN (GUAR4)

Iguacu Cafe ON (IGUA3)

Ipiranga Pet PN (PTIP4)

Klabin S/A ON (KLBN3)

Leco PN (LECO4)

Marcopolo ON (POMO3)

Randon Part PN (RAPT4)

Ripasa PN (RPSA4)

Sergen PN (SGEN4)

Sid Nacional ON (CSNA3)

Springer PNB (SPRI6)

Suzano Papel PNA (SUZB5)

Valefert PN (FFTL4)

Vigor PN (VGOR4)

Wetzel S/A PN (MWET4)

Whirlpool PN (WHRL4) 
Granoleo PN (GRNL4)

Inds Romi PN (ROMI4)

Iochp.Maxion PN (MYPK4)

Ipiranga Dis ON (DPPI3)

Ipiranga Ref ON (RIPI3)

Itautec ON (ITEC3)

Lix da Cunha ON (LIXC3)

Lojas Americ ON (LAME3)

Lojas Hering ON (LHER3)

Magnesita ON (MAGS3)

Manasa PN (MNSA4)

Mangels Indl PN (MGEL4)

Marisol PN (MRSL4)

Mendes Jr PNB (MEND6)

Metal Leve PN (LEVE4)

Metisa PN (MTSA4)

Oi ON (OIBR3)

Panatlantica PN (PATI4)

Paranapanema ON (PMAM3)

Pet Manguinh PN (RPMG4)

Petrobras PN (PETR4)

Petroflex ON (PEFX3)

Politeno PNB (PLTO6)

Pronor PNA (PNOR5)

Rasip Agro ON (RSIP3)

Rede Energia ON (REDE3)

Riosulense PN (RSUL4)

Sabesp ON (SBSP3)

Sadia S/A PN (SDIA4)

Sansuy PNA (SNSY5)

Saraiva Livr ON (SLED3)

Souza Cruz ON (CRUZ3)

Teka PN (TEKA4)

Tekno PN (TKNO4)

Tele Sudeste Celula ON (TSEP3)

Telef Brasil ON (VIVT3)

Telemar PN (TNLP4)

Telemig Part ON (TMCP3)

Tim Part S/A PN (TCSL4) 
Tim Sul ON (TPRC3)

Trafo ON (TRFO3)

Tupy ON (TUPY3)

Ultrapar PN (UGPA4)

Usiminas PNB (USIM6)

Vale PNA (VALE5)

Vivo ON (VIVO3)

Weg ON (WEGE3) 
Tabela 18 - Lista de Empresas Exercício Governador 2006

Exercício Governador 2006

\begin{tabular}{|c|c|}
\hline Empresas Não Doadoras & Empresas Doadoras \\
\hline AES Elpa ON (AELP3) & Alpargatas PN (ALPA4) \\
\hline AES Tiete ON (GETI3) & Aracruz PNA (ARCZ5) \\
\hline Alfa Holding PNA (RPAD5) & Braskem ON (BRKM3) \\
\hline Ambev S/A PN (AMBV4) & Dimed ON (PNVL3) \\
\hline Ampla Energ ON (CBEE3) & Ferbasa PN (FESA4) \\
\hline Bardella ON (BDLL3) & Forja Taurus PN (FJTA4) \\
\hline Baumer ON (BALM3) & Grazziotin ON (CGRA3) \\
\hline Bic Monark ON (BMKS3) & Guararapes PN (GUAR4) \\
\hline Bombril PN (BOBR4) & Itautec ON (ITEC3) \\
\hline Botucatu Tex PN (STRP4) & Klabin S/A PN (KLBN4) \\
\hline CCR SA ON (CCRO3) & Marcopolo ON (POMO3) \\
\hline Cacique ON (CIQU3) & P.Acucar.Cbd PN (PCAR4) \\
\hline Ceb PNA (CEBR5) & Quattor Petr PN (SZPQ4) \\
\hline Celpa PNC (CELP7) & Randon Part ON (RAPT3) \\
\hline Cemig ON (CMIG3) & Sadia S/A PN (SDIA4) \\
\hline Coelce ON (COCE3) & Sid Nacional ON (CSNA3) \\
\hline Comgas ON (CGAS3) & Tectoy ON (TOYB3) \\
\hline Const A Lind PN (CALI4) & Unipar ON (UNIP3) \\
\hline Cosern PNA (CSRN5) & Vale ON (VALE3) \\
\hline Docas ON (DOCA3) & Valefert PN (FFTL4) \\
\hline Elekeiroz PN (ELEK4) & Wetzel S/A PN (MWET4) \\
\hline Elektro PN (EKTR4) & Whirlpool PN (WHRL4) \\
\hline \multicolumn{2}{|l|}{ Eletrobras PNA (ELET5) } \\
\hline \multicolumn{2}{|l|}{ Eletropaulo PNA (ELPL5) } \\
\hline \multicolumn{2}{|l|}{ Embratel Part PN (EBTP4) } \\
\hline \multicolumn{2}{|l|}{ Energisa Mt ON (ENMT3) } \\
\hline \multicolumn{2}{|l|}{ Fibam PN (FBMC4) } \\
\hline \multicolumn{2}{|l|}{ Fras.Le PN (FRAS4) } \\
\hline \multicolumn{2}{|l|}{ Gerdau Met ON (GOAU3) } \\
\hline \multicolumn{2}{|l|}{ Itausa PN (ITSA4) } \\
\hline \multicolumn{2}{|l|}{ Karsten PN (CTKA4) } \\
\hline \multicolumn{2}{|l|}{ Lix da Cunha PN (LIXC4) } \\
\hline \multicolumn{2}{|l|}{ Lojas Americ ON (LAME3) } \\
\hline Mangels Indl PN (MGEL4) & \\
\hline
\end{tabular}


Marisol PN (MRSL4)

Melhor SP ON (MSPA3)

Metal Leve PN (LEVE4)

Metisa PN (MTSA4)

Mont Aranha ON (MOAR3)

Oi PN (OIBR4)

Panatlantica ON (PATI3)

Par Al Bahia PN (PEAB4)

Paranapanema ON (PMAM3)

Petrobras ON (PETR3)

Rasip Agro ON (RSIP3)

Rede Energia ON (REDE3)

Riosulense PN (RSUL4)

Rossi Resid ON (RSID3)

Sabesp ON (SBSP3)

Sanepar PN (SAPR4)

Saraiva Livr PN (SLED4)

Souza Cruz ON (CRUZ3)

Telef Brasil PN (VIVT4)

Telemig Part ON (TMCP3)

Tim Part S/A PN (TCSL4)

Tupy ON (TUPY3)

Usiminas PNB (USIM6)

Vivo ON (VIVO3)

Weg ON (WEGE3)

Wlm Ind Com ON (SGAS3) 
Tabela 19 - Lista de Empresas Exercício Governador 2010

Exercício Governador 2010

\begin{tabular}{|c|c|}
\hline Empresas Não Doadoras & Empresas Doadoras \\
\hline AES Elpa ON (AELP3) & Alpargatas ON (ALPA3) \\
\hline AES Tiete ON (GETI3) & BRF SA ON (BRFS3) \\
\hline Afluente ON (AFLU3) & BmfBovespa ON (BVMF3) \\
\hline Alfa Consorc ON (BRGE3) & Braskem ON (BRKM3) \\
\hline Alfa Holding ON (RPAD3) & Cedro ON (CEDO3) \\
\hline All Amer Lat ON (ALLL3) & Celul Irani ON (RANI3) \\
\hline Ambev S/A ON (ABEV3) & Cia Hering ON (HGTX3) \\
\hline Ampla Energ ON (CBEE3) & Contax ON (CTAX3) \\
\hline Ampla Invest ON (AMPI3) & Cosan ON (CSAN3) \\
\hline Arteris ON (ARTR3) & Csu Cardsyst ON (CARD3) \\
\hline BHG ON (BHGR3) & Dasa ON (DASA3) \\
\hline BR Brokers ON (BBRK3) & Dimed ON (PNVL3) \\
\hline BR Malls Par ON (BRML3) & Embraer ON (EMBR3) \\
\hline Bematech ON (BEMA3) & Eternit ON (ETER3) \\
\hline Bic Monark ON (BMKS3) & Fer Heringer ON (FHER3) \\
\hline Brasilagro ON (AGRO3) & Ferbasa ON (FESA3) \\
\hline Brookfield ON (BISA3) & Grendene ON (GRND3) \\
\hline CCR SA ON (CCRO3) & Guararapes ON (GUAR3) \\
\hline CPFL Energia ON (CPFE3) & Hypermarcas ON (HYPE3) \\
\hline Cacique ON (CIQU3) & Inds Romi ON (ROMI3) \\
\hline Casan ON (CASN3) & JBS ON (JBSS3) \\
\hline Ceb ON (CEBR3) & Klabin S/A ON (KLBN3) \\
\hline Celesc ON (CLSC3) & M.Diasbranco ON (MDIA3) \\
\hline Cemar ON (ENMA3B) & MRV ON (MRVE3) \\
\hline Cemig ON (CMIG3) & Marcopolo ON (POMO3) \\
\hline Cesp ON (CESP3) & Marfrig ON (MRFG3) \\
\hline Coelba ON (CEEB3) & Multiplan ON (MULT3) \\
\hline Coelce ON (COCE3) & Paranapanema ON (PMAM3) \\
\hline Comgas ON (CGAS3) & Profarma ON (PFRM3) \\
\hline Copasa ON (CSMG3) & Randon Part ON (RAPT3) \\
\hline Copel ON (CPLE3) & Rossi Resid ON (RSID3) \\
\hline Cosern ON (CSRN3) & Santanense ON (CTSA3) \\
\hline Coteminas ON (CTNM3) & Sao Martinho ON (SMTO3) \\
\hline Cremer ON (CREM3) & Sultepa ON (SULT3) \\
\hline
\end{tabular}




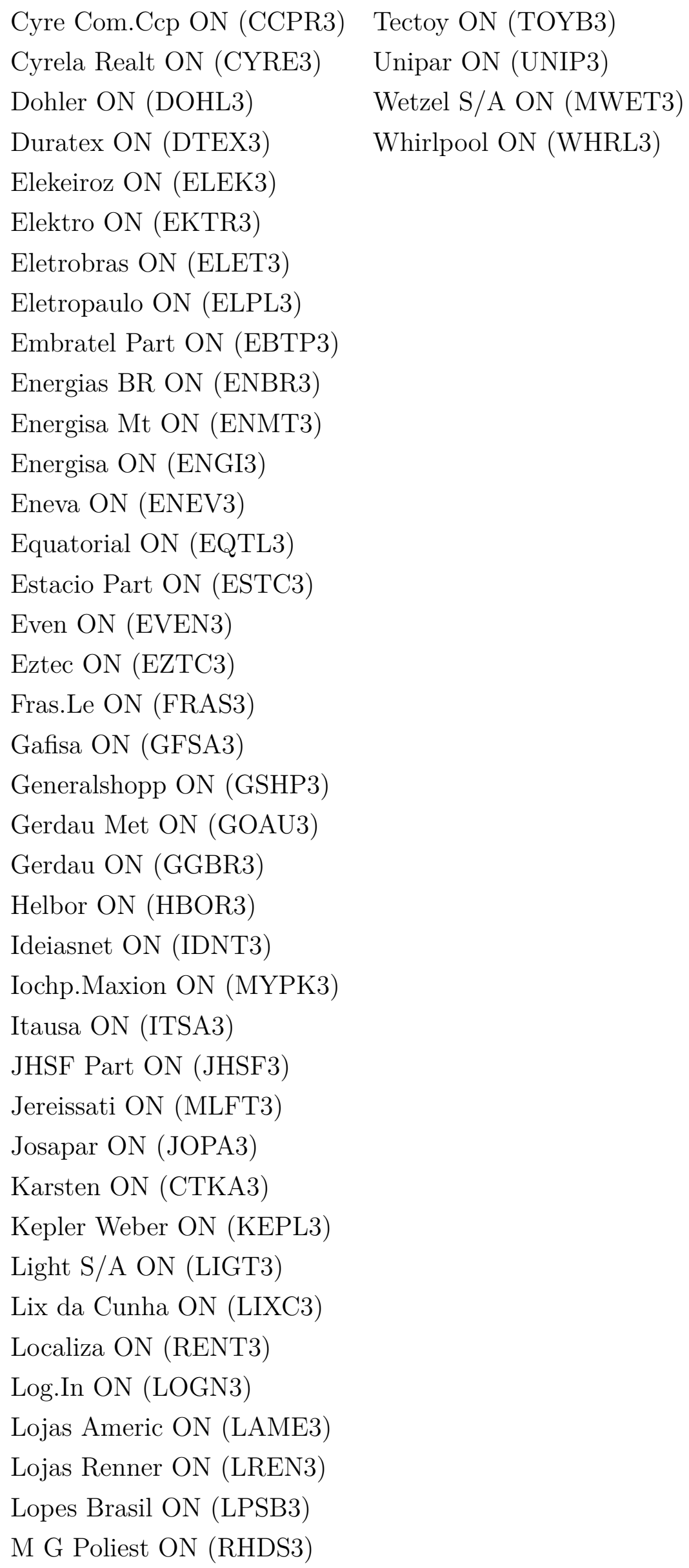


MMX Miner ON (MMXM3)

Magnesita SA ON (MAGG3)

Melhor SP ON (MSPA3)

Metalfrio ON (FRIO3)

Mont Aranha ON (MOAR3)

Natura ON (NATU3)

Net ON (NETC3)

Odontoprev ON (ODPV3)

Oi ON (OIBR3)

Panatlantica ON (PATI3)

Par Al Bahia ON (PEAB3)

Petrobras ON (PETR3)

Plascar Part ON (PLAS3)

Portobello ON (PTBL3)

Prumo ON (PRML3)

RaiaDrogasil ON (RADL3)

Rasip Agro ON (RSIP3)

Recrusul ON (RCSL3)

Rodobensimob ON (RDNI3)

SLC Agricola ON (SLCE3)

Sabesp ON (SBSP3)

Sao Carlos ON (SCAR3)

Saraiva Livr ON (SLED3)

Souza Cruz ON (CRUZ3)

Springer ON (SPRI3)

Springs ON (SGPS3)

Tecnisa ON (TCSA3)

Tegma ON (TGMA3)

Telef Brasil ON (VIVT3)

Tempo Part ON (TEMP3)

Tim Part S/A ON (TIMP3)

Totvs ON (TOTS3)

Tractebel ON (TBLE3)

Tran Paulist ON (TRPL3)

Trisul ON (TRIS3)

Triunfo Part ON (TPIS3)

Tupy ON (TUPY3)

Usiminas ON (USIM3)

Viver ON (VIVR3) 
Vulcabras ON (VULC3)

Weg ON (WEGE3)

Wlm Ind Com ON (SGAS3) 